\title{
Reduction in biomass burning aerosol light absorption upon humidification: roles of inorganically-induced hygroscopicity, particle collapse, and photoacoustic heat and mass transfer
}

\author{
K. A. Lewis ${ }^{1}$, W. P. Arnott ${ }^{1}$, H. Moosmüller ${ }^{2}$, R. K. Chakrabarty ${ }^{2}$, C. M. Carrico ${ }^{3}$, S. M. Kreidenweis ${ }^{3}$, D. E. Day ${ }^{4}$, \\ W. C. Malm ${ }^{4}$, A. Laskin ${ }^{5}$, J. L. Jimenez ${ }^{6}$, I. M. Ulbrich ${ }^{6}$, J. A. Huffman ${ }^{6,}$, T. B. Onasch ${ }^{7}$, A. Trimborn ${ }^{7}$, L. Liu ${ }^{8}$, and \\ M. I. Mishchenko ${ }^{8}$ \\ ${ }^{1}$ Department of Physics, University of Nevada, Reno, NV 89557, USA \\ ${ }^{2}$ Division of Atmospheric Sciences, Desert Research Institute, Nevada, System of Higher Education, Reno, NV 89512, USA \\ ${ }^{3}$ Department of Atmospheric Science, Colorado State University, Ft. Collins, CO 80523, USA \\ ${ }^{4}$ Cooperative Institute for Research of the Atmosphere/National Park Service, Colorado State University, \\ Ft. Collins, CO 80523, USA \\ ${ }^{5}$ William R. Wiley Environmental Molecular Sciences Laboratory, Pacific Northwest National Laboratory, \\ Richland, WA 99352, USA \\ ${ }^{6}$ Department of Chemistry and Biochemistry and Cooperative Institute for Research in the Environmental Sciences (CIRES), \\ University of Colorado at Boulder, Boulder, CO 80309, USA \\ ${ }^{7}$ Aerodyne Research Inc., Center of Aerosol and Cloud Chemistry, Billerica, Massachusetts 01821, USA \\ ${ }^{8}$ NASA Goddard Institute for Space Studies, New York, NY 10025, USA \\ "now at: Max Planck Institute for Chemistry, Mainz, Germany
}

Received: 24 June 2009 - Published in Atmos. Chem. Phys. Discuss.: 15 July 2009

Revised: 30 October 2009 - Accepted: 2 November 2009 - Published: 27 November 2009

\begin{abstract}
Smoke particle emissions from the combustion of biomass fuels typical for the western and southeastern United States were studied and compared under high humidity and ambient conditions in the laboratory. The fuels used were Montana ponderosa pine (Pinus ponderosa), southern California chamise (Adenostoma fasciculatum), and Florida saw palmetto (Serenoa repens). Information on the nonrefractory chemical composition of biomass burning aerosol from each fuel was obtained with an aerosol mass spectrometer and through estimation of the black carbon concentration from light absorption measurements at $870 \mathrm{~nm}$. Changes in the optical and physical particle properties under high humidity conditions were observed for hygroscopic smoke particles containing substantial inorganic mass fractions that were emitted from combustion of chamise and palmetto fuels. Light scattering cross sections increased under high humidity for these particles, consistent with the hygroscopic growth measured for $100 \mathrm{~nm}$ particles in HTDMA measurements.
\end{abstract}

Photoacoustic measurements of aerosol light absorption coefficients revealed a $20 \%$ reduction with increasing relative humidity, contrary to the expectation of light absorption enhancement by the liquid coating taken up by hygroscopic particles. This reduction is hypothesized to arise from two mechanisms: (1) shielding of inner monomers after particle consolidation or collapse with water uptake; (2) the lower case contribution of mass transfer through evaporation and condensation at high relative humidity $(\mathrm{RH})$ to the usual heat transfer pathway for energy release by laser-heated particles in the photoacoustic measurement of aerosol light absorption. The mass transfer contribution is used to evaluate the fraction of aerosol surface covered with liquid water solution as a function of $\mathrm{RH}$. 


\section{Introduction}

Light absorbing particles often are formed by incomplete combustion of carbonaceous materials and are released by sources such as industrial plants, vehicle emissions, and biomass burning. Such particles, generically referred to as black carbon or soot, form an important but not wellunderstood category of aerosols with dramatic radiative impact and climatic implications. This uncertainty is due in part to variability in global distribution and mixing state, along with complex soot morphology and internal composition (Jacobson, 2001). Characterization of biomass burning emissions can make an important contribution to understanding properties of ambient aerosols because biomass burning provides a significant source of airborne particulate matter worldwide (Bond et al., 2004). This source may increase in the future due to the influence of global and regional warming on wildfire activity (Westerling et al., 2006). The radiative impact of smoke on atmospheric temperature is highly uncertain (Solomon et al., 2007), partially because the suspended particles can have both direct and indirect effects on atmospheric radiation transfer (Ramanathan et al., 2001). Additional variability in the radiative impact of biomass burning aerosol is provided by a number of factors including combustion conditions and morphological properties of the aerosol particles, as well as other factors discussed in this manuscript: the fractal dimension and collapse of the particles and effects of aerosol aging such as coating enhancement.

Fresh, dry soot particles generally can be characterized as fractal-like chain aggregates consisting of small $(30-50 \mathrm{~nm}$ diameter) spherical monomers. The following scaling law, which relates the number of monomers, $N$, to the radius of gyration of the cluster, $R_{g}$, is useful in describing soot morphology (Chakrabarty et al., 2007; Köylü et al., 1995; Liu et al., 2008; Sorensen, 2001):

$N=k_{o}\left(R_{g} / a\right)^{D}$,

where $k_{o}$ is the fractal prefactor, $a$ is the mean monomer radius, and $D$ is the mass or density fractal dimension. The radius of gyration of the particle provides a measure of the overall cluster radius, and both the non-integer fractal dimension and fractal prefactor characterize monomer distribution and fractal morphology. The fractal dimension, $D$, describes the space-filling characteristics of the aggregate. $D$ is equal to 3 for a sphere and 1 for a perfectly linear particle, corresponding to extremes on either end of the scale. Numerous experimental and simulation studies have used Eq. (1) to characterize the structure of aggregates from various combustion sources. For aggregates formed during high temperature combustion, in which the monomers or clusters meet each other through random motion and stick together with near unity probability (referred to as diffusion-limited cluster aggregation; DLCA; Sorensen, 2001), $D$ has been reported to lie between 1.6 and 1.8 (Chakrabarty et al., 2006;
Köylü et al., 1995; Sorensen, 2001). The level of compactness of the fractal-like particle also is related to fractal prefactor $k_{o}$, with lesser packing density for smaller values of $k_{o}$ at fixed $D$. The value of $k_{o}$ for combustion aerosols formed via DLCA has been found to be near unity (Sorensen and Roberts, 1997). The branched, open morphology of a soot particle immediately following combustion generation (corresponding to $D \approx 1.8$ ) is expected to become more compact (i.e. $D>1.8$ ) with age. Therefore, the value of $D$ may be correlated with the particle's history and is important in determining its optical properties (Liu et al., 2008).

The 2006 Fire Lab at Missoula Experiment (FLAME-1) was the first of two major campaigns to study particulate matter emissions by wildland fires relevant to visibility impairment, climate impacts, and airborne particulate matter (PM) standards (Moosmüller et al., 2007). It took place at the United States Forest Service Fire Sciences Laboratory in Missoula, Montana during June 2006. The campaign involved laboratory characterization of emissions from the controlled combustion of mostly North American fuels (McMeeking et al., 2009). Optical, physical, and chemical properties of the biomass smoke were measured along with emission rates. A chamber burn experiment consisted of a brief (typically 5-10 min) burn of about $200 \mathrm{~g}$ of fuel with the smoke being trapped in the large, enclosed combustion chamber and sampled during a two-hour period (McMeeking et al., 2009). Further description of the FLAME campaigns, including a detailed description of the experimental set up for the chamber burns and fuel list, can be found in other publications (Lewis et al., 2008; Moosmüller et al., 2007) and at the FLAME website (http://chem.atmos.colostate.edu/ FLAME/).

This manuscript presents results concerning light scattering and absorption by the smoke from combustion of three representative biomass fuels under varying humidity conditions. The optical properties of particles depended strongly on relative humidity $(\mathrm{RH})$, fuel type and particle composition, hygroscopicity, and morphology. Very little change in light scattering and absorption upon humidification was measured for mostly hydrophobic particles that showed little adsorption of water vapor and hygroscopic growth. Results were more complex for the more hygroscopic particles where light scattering increased with rising $\mathrm{RH}$ and water uptake while measured light absorption actually decreased. This is contrary to the theoretical prediction that the presence of a non-absorbing coating surrounding a soot core leads to enhancement of light absorption (Bond et al., 2006). Our work seeks to understand the changing optical properties of the smoke aerosol in light of particle morphology and measurement circumstances. 


\section{Experimental approach}

\subsection{Instrumentation}

Several state-of-the-art instruments were used in this study. Photoacoustic instrumentation was used to quantify aerosol light absorption at $870 \mathrm{~nm}$ (Arnott et al., 1999). Measurements of light scattering coefficient were obtained from reciprocal nephelometry (Abu-Rahmah et al., 2006) within the photoacoustic instrument's resonator. Two integrating nephelometers operating at $530 \mathrm{~nm}$ (Radiance Research Model 903) also were deployed to quantify light scattering by particles (Day et al., 2006). Size and chemically-resolved mass loading information for the emitted particulates was provided by a high-resolution aerosol mass spectrometer (HR-ToF-AMS, hereinafter "AMS") (Aerodyne Research, Inc.) (Canagaratna et al., 2007; DeCarlo et al., 2006). A Hygroscopic Tandem Differential Mobility Analyzer (HTDMA) designed to measure the response of an aerosol size distribution to changing relative humidity conditions also was used (Carrico et al., 2008; Liu et al., 1978; Rader and McMurry, 1986). During a few select burns, a nucleopore filter sampled particulate matter that was imaged using a scanning electron microscope (SEM) (Hitachi, Inc.). SEM images were obtained for ambient and humidified chamise smoke particles during the FLAME-1 campaign. Further analysis of particles deposited on a grid-supported thin film substrate was conducted using scanning electron microscopy with energy dispersed analysis of X-rays (SEM/EDX) (FEG XL30, FEI, Inc), as described by Laskin et al. (2006).

To further assess the hygroscopic properties of smoke from each fuel, one photoacoustic instrument and one integrating nephelometer were set up in series on each of two channels: an ambient, unmodified smoke sample directly from the burn chamber (the "dry" channel), and a humidified ("wet") channel. Variable RH on the wet channel was controlled by a Perma Pure moisture exchange membrane. During the course of two-hour sampling from a chamber burn, $\mathrm{RH}$ was increased from the ambient level of the chamber (around 20\%) up to near 80\%, and then brought back down to the original "dry" conditions.

\subsection{Fuels}

The fuels chosen for the FLAME- 1 campaign commonly burn in western and southeastern United States' wildland fires. The three fuels examined in detail here represent distinct species and plant types from different parts of the country. The shrub chamise (Adenostoma fasciculatum) is a dominant species from the southern California chaparral ecosystem. Samples of chamise were collected from the San Jacinto Mountains in southern California. Needles, branches, and litter (dead material from the forest floor) of the coniferous species ponderosa pine (Pinus ponderosa) also were burned. Ponderosa pine fuel samples were collected from rural locations near Missoula, Montana. The third fuel examined was palmetto (Serenoa repens), an understory shrub familiar to the coastal plain region of the southeastern United States. Palmetto samples were collected from Florida and Mississippi. The fuel moisture content for each of these three fuels was near $10 \%$ (dry weight percentage). This moisture content does not necessarily represent the fuel moisture content in the field due to losses during shipping and storage (McMeeking, 2008).

\section{Measurements}

\subsection{Photoacoustic and nephelometer measurements: absorption, scattering, and $f_{\mathrm{RH}}$}

Time resolved measurements of light scattering and absorption coefficients with an integrating nephelometer and photoacoustic instruments are shown in Figs. 1 and 3, respectively, for particles emitted from the combustion of three fuels. Scattering and absorption coefficients measured at 530 and $870 \mathrm{~nm}$ by nephelometer and photoacoustic instruments on the dry and humidified channels are presented in units of $\mathrm{Mm}^{-1}$ as a function of sample time and correspond to the left vertical axis on the figures. The right vertical axis refers to changing RH conditions of the humidified sample with time, as measured by a humidity sensor installed inside of the photoacoustic instrument. The RH record of the ambient channel is not included in the figures as it remained steady throughout the course of each $2 \mathrm{~h}$ experiment. For the ponderosa pine and chamise burns presented in Fig. 1a and b, the "dry" RH remained relatively constant around $19 \%$ and never surpassed $23 \%$. The average RH of the palmetto burn was lower at just under $16 \%$.

Light scattering coefficients are presented for ponderosa pine, chamise, and palmetto in Fig. 1a, b, and c, respectively. Measurements at $530 \mathrm{~nm}$ were made by integrating nephelometers and those at $870 \mathrm{~nm}$ were made by photoacoustic instruments employing reciprocal nephelometry. Large scattering background found on the dry channel of the $870 \mathrm{~nm}$ instrument renders a large standard deviation in those measurements, which are scattered around the baseline of low $\mathrm{RH}$ (below $40 \%$ ) measurements on the $870 \mathrm{~nm}$ humidified channel. The $870 \mathrm{~nm}$ ambient time series data shown in Fig. 1a, $\mathrm{b}$ and $\mathrm{c}$ is a linear fit using the humidified channel baseline. The fit data is added to provide a visual reference for the constant scattering expected for slowly decreasing aerosol levels over the course of a two-hour sample under ambient RH conditions. Measured light scattering coefficients at both $530 \mathrm{~nm}$ and $870 \mathrm{~nm}$ for particles from the combustion of two of the three fuels exhibit strong dependence on humidity. A minor increase in scattering occurs for $\mathrm{RH}$ above $74 \%$ by ponderosa pine smoke, while much more dramatic increases in scattering coefficients are observed for smoke aerosols from burns of chamise and palmetto. For chamise smoke, 


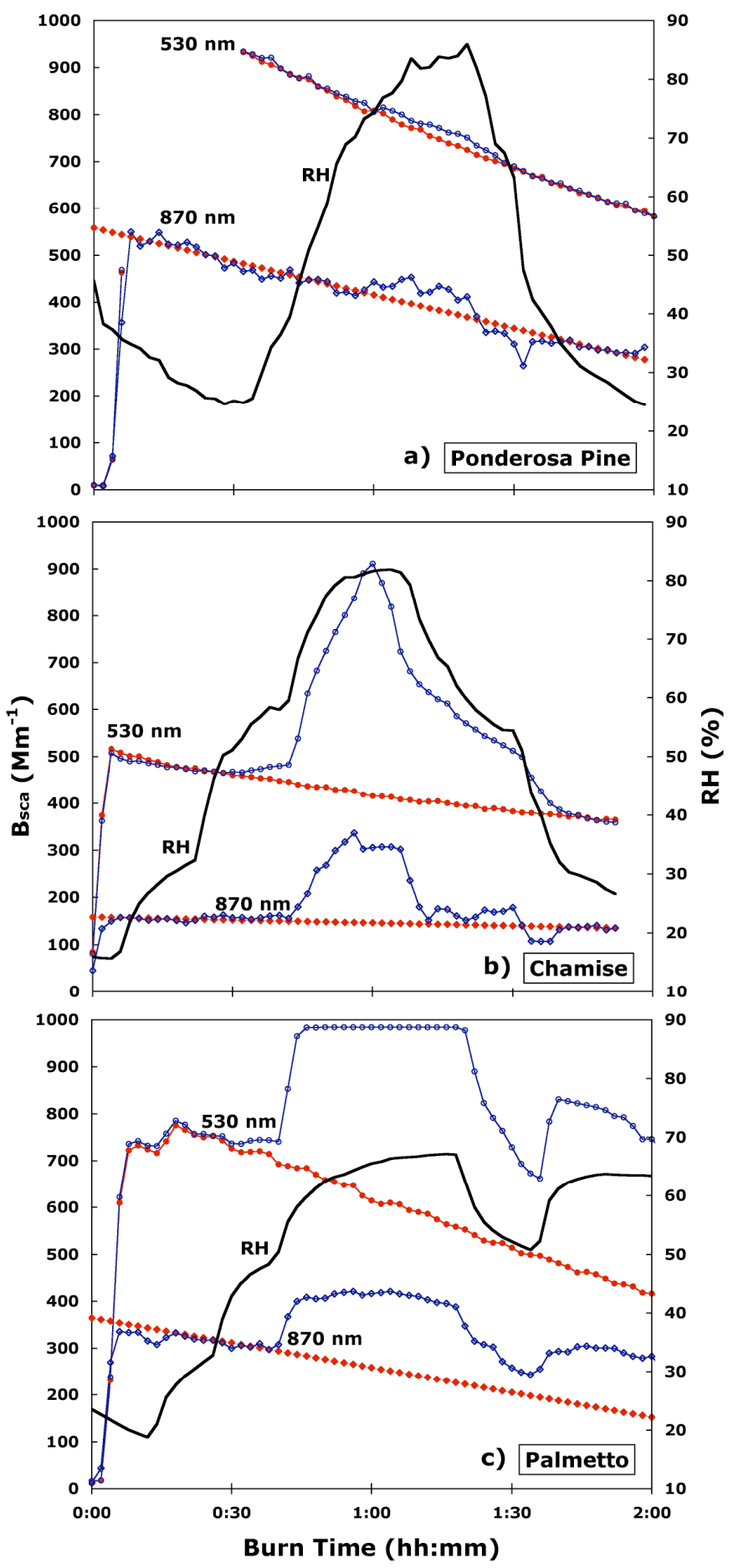

Fig. 1. Coefficients of scattering in $\mathrm{Mm}^{-1} \beta_{\text {sca }}$ measured by an integrating nephelometer $(530 \mathrm{~nm})$ and reciprocal nephelometer $(870 \mathrm{~nm})$ for a burn of (a) ponderosa pine, (b) chamise, and (c) palmetto fuel on two channels, including percent RH of the humidified channel. Measurements on the humidified channel are depicted in blue, while those on the ambient (dry) channel are in red. light scattering coefficients begin to increase as increasing $\mathrm{RH}$ reaches about $55 \%$, while for palmetto this threshold is even lower at around $48 \%$.

Changes in aerosol sample optical properties with increasing $\mathrm{RH}$ are presented in terms of the hygroscopic scattering growth factor, $f_{\mathrm{RH}, \mathrm{sca}}$, and the hygroscopic absorption growth factor, $f_{\mathrm{RH}, \mathrm{abs}}$, in Figs. 2 and 4 , respectively. The hygroscopic growth factor for light absorption/scattering is defined as the light absorption/scattering coefficient measured by the humidified (wet) channel divided by the absorption/scattering coefficient measured by the ambient (dry) channel (Day et al., 2006):

$f_{\mathrm{RH}(\mathrm{abs}, \mathrm{sca})}=\frac{\beta_{\mathrm{abs}, \mathrm{sca}}(\mathrm{RH})}{\beta_{\mathrm{abs}, \mathrm{sca}}(\mathrm{dry})}$.

Panels a and b of Fig. 2 show hygroscopic scattering growth factor, $f_{\mathrm{RH}, \mathrm{sca}}$, as a function of $\mathrm{RH}$ for $530 \mathrm{~nm}$ and $870 \mathrm{~nm}$ scattering coefficient measurements, respectively. At both wavelengths the minor increase in aerosol light scattering for ponderosa pine smoke can be contrasted with the far more dramatic increase for chamise and palmetto smoke aerosols. The effect occurs at lower RH levels for smoke from these two fuels. The palmetto light-scattering growth factor exceeds 1.8, and for chamise it reaches 2.2.

Measurements of light absorption coefficients under rising RH conditions show the opposite effect: a decrease in measured values is found, but only for certain fuels. Light absorption properties of the ponderosa pine smoke show no dependence on the RH of the surrounding air, as exhibited in Fig. 3a. This is in sharp contrast to smoke from chamise and palmetto burns, in Fig. $3 \mathrm{~b}$ and c, respectively, for which measured light absorption coefficients decrease when the relative humidity reaches some critical level.

In Fig. $4, f_{\mathrm{RH} \text {,abs }}$ is given as a function of the humidified sample RH. Figure 4 reveals the different levels of reduction in light absorption observed for smoke from each fuel type. For ponderosa pine, $f_{\mathrm{RH} \text {,abs }}$ is noisy but remains constant around unity, while $f_{\mathrm{RH} \text {,abs }}$ for chamise drops below unity for $\mathrm{RH}$ conditions greater than $60 \%$. For palmetto, $f_{\mathrm{RH}}$,abs is increasingly negative for $\mathrm{RH}$ values above $50 \%$. The remainder of this paper interprets these results.

\subsection{Composition and morphology}

Hygroscopic properties of smoke particles are related to aerosol composition. Information regarding the organic mass $(\mathrm{OM})$ versus non-refractory inorganic fractions of the smoke from each fuel was compiled using AMS composition measurements, shown in Fig. 5a, b, and c. The AMS measures non-refractory aerosol components (operationally defined as particle mass that does not flash vaporize at $600^{\circ} \mathrm{C}$ ) at aerodynamic diameters of less than $\sim 1 \mu \mathrm{m}$ (NR-PM ${ }_{1}$ ) (Canagaratna et al., 2007). These measurements represent lower limits on mass loadings due to uncertainty in collection efficiencies for biomass burning particles. Also included in these 
figures is the black carbon (BC) concentration, derived by dividing the $870 \mathrm{~nm}$ photoacoustic light absorption coefficient measurements at ambient RH by a specific mass absorption efficiency consistent with the range of values reported by Bond and Bergstrom (2006) of $8.8 \mathrm{~m}^{2} / \mathrm{g}$ for $532 \mathrm{~nm}$, adjusted for inverse wavelength dependence of light absorption by $\mathrm{BC}$.

Ponderosa pine smoke particle composition is overwhelmingly dominated by organic components, which make up $97.8 \%$ of the total mass. In contrast, the organic fraction of the chamise smoke particles makes up just under $50 \%$ of the total mass, and for palmetto smoke the aerosol mass fraction of organic material is lower still at $42.8 \%$. The largest $\mathrm{BC}$ fraction is found for chamise smoke particles, where $\mathrm{BC}$ comprises $27 \%$ of the total mass.

Increased hygroscopicity of biomass smoke aerosol particles scales with the percentage composition of alkali species in the fuel (Rissler et al., 2005). In the combustion aerosol, the alkali species are in the form of inorganic materials, such as sodium or potassium salts. Emissions from the palmetto burn were unique in that they were dominated by inorganic compounds, with chlorine and ammonium comprising the highest percentage by mass. The hygroscopicity of chamise also is explainable by the particle composition, with nearly a quarter of the particle mass comprised of inorganic components. The inorganic compounds of ponderosa pine smoke particles, in contrast, make up less than $1 \%$ of the total particle mass.

Variations in chemical composition for ponderosa pine, chamise, and palmetto wood smokes, as determined by AMS measurements, are consistent with a classification proposed by Hopkins et al. (2007a) based on X-ray and electron microscopy measurements. That work reported three major particle-type categories based on chemical and optical properties: (1) materials composed of liquid/oily organic carbon (OC) and BC with no inorganic inclusions (e.g., ponderosa pine combustion particles), (2) non-homogenous mixture of carbonaceous and inorganic materials (e.g., palmetto combustion particles), and (3) BC material with fractal morphology typical of soot containing inorganic inclusions (e.g., chamise combustion particles). These three categories also were characterized by $\mathrm{sp}^{2}$ hybridization, which was calculated from near-edge X-ray absorption fine structure (NEXAFS) spectra (Hopkins et al., 2007b). The fraction of $\mathrm{sp}^{2}$ hybridization reveals the graphitic nature of the material: $100 \% \mathrm{sp}^{2}$ hybridization is consistent with strongly aligned pyrolytic graphite. The three groups of combustion products were increasingly graphitic in nature, such that the mean $\mathrm{sp}^{2}$ hybridization of the category 1, 2, and 3 fuels was 34\%,53\%, and $83 \%$, respectively (Hopkins et al., 2007a).

To explore the unexpected decrease in aerosol light absorption by smoke from certain fuel types, SEM images were acquired for ambient and humidified chamise smoke particles deposited on filter substrates. Ambient RH, or "dry", chamise smoke particles are comprised of fractal-like chain aggregates of spherical particles (i.e., monomers), typical of BC aerosol, as can be seen in Fig. 6 (Chakrabarty et al., 2007). After exposure to high RH conditions (i.e., $\mathrm{RH}>80 \%$ ), chamise particles are observed to have collapsed into a more compact, near-spherical structure. The SEM images of humidified smoke from a burn of chamise fuel presented in Fig. 7 reveal collapse of the formerly fractal-like aerosol particles after exposure to increased humidity. Figure $7 \mathrm{~b}$ is a close-up view of a single particle of chamise smoke after exposure to high RH conditions. The surface area of a collapsed particle is reduced to the order of the surface area of a single sphere with the diameter of the particle, as opposed to the combined surface area of the many spherules comprising a dry particle of fractal nature. Additionally, particle "diameter", or a measure of the length of the particle spanning its largest dimension, decreases with particle collapse.

Additional SEM images of dry biomass burning particles collected during a chamise burn are shown in Fig. 8, along with characteristic X-ray spectra for the chamise smoke particles. The figure includes images of the same sample area obtained using secondary electron (SE) and backscattered electron (BSE) detectors, in Fig. 8a and b, respectively. Carbonaceous soot has very low backscattered electron yield compared to that of higher $\mathrm{Z}$ materials, so the soot particles are largely invisible in the BSE image, while their detailed structure is revealed from the SE image (Laskin et al., 2006). Comparing the SE and BSE images in Fig. 8 reveals the fractal-like structure of the carbonaceous material composing the chamise combustion particles along with inorganic inclusions of higher density materials seen as bright spots in the BSE image. Figure 8c shows results of the SEM/EDX analysis of the numbered bright areas marked in Fig. 8b. In principle, intensities of peaks in the X-ray spectra are quantitatively related to the elemental composition of particles. The relative ratios of $\mathrm{K}, \mathrm{Na}, \mathrm{Cl}$, and $\mathrm{S}$ can be well quantified, whereas accuracy of the detection of $\mathrm{C}, \mathrm{N}$, and $\mathrm{O}$ is constrained by the substrate background signal and other factors (Laskin and Cowin, 2001; Laskin et al., 2006). The Xray spectra of the bright spots in the BSE image of Fig. 8 indicate that these are inorganic inclusions of mixed $\mathrm{KCl}$ and $\mathrm{K}_{2} \mathrm{SO}_{4}$ composition. The $\mathrm{Cu}$ signal is from the substrate background. This composition analysis is in qualitative agreement with the AMS measurements presented in Fig. $5 \mathrm{~b}$.

An SEM image of ponderosa pine combustion particles is shown in Fig. 9, revealing soot inclusions inside of liquid/oily organic substances. The particles appear as fractallike aggregates, with ponderosa pine needle combustion particles being more compact (higher fractal dimension) than observed for chamise. EDX analysis of the dark, oily areas as well as of the bright solid particle cores show almost no elements other than carbon and oxygen, again consistent with the AMS/photoacoustic analysis. The limited scope of a few SEM images of single particles makes it difficult to characterize the aerosol in its entirety. The images suggest 

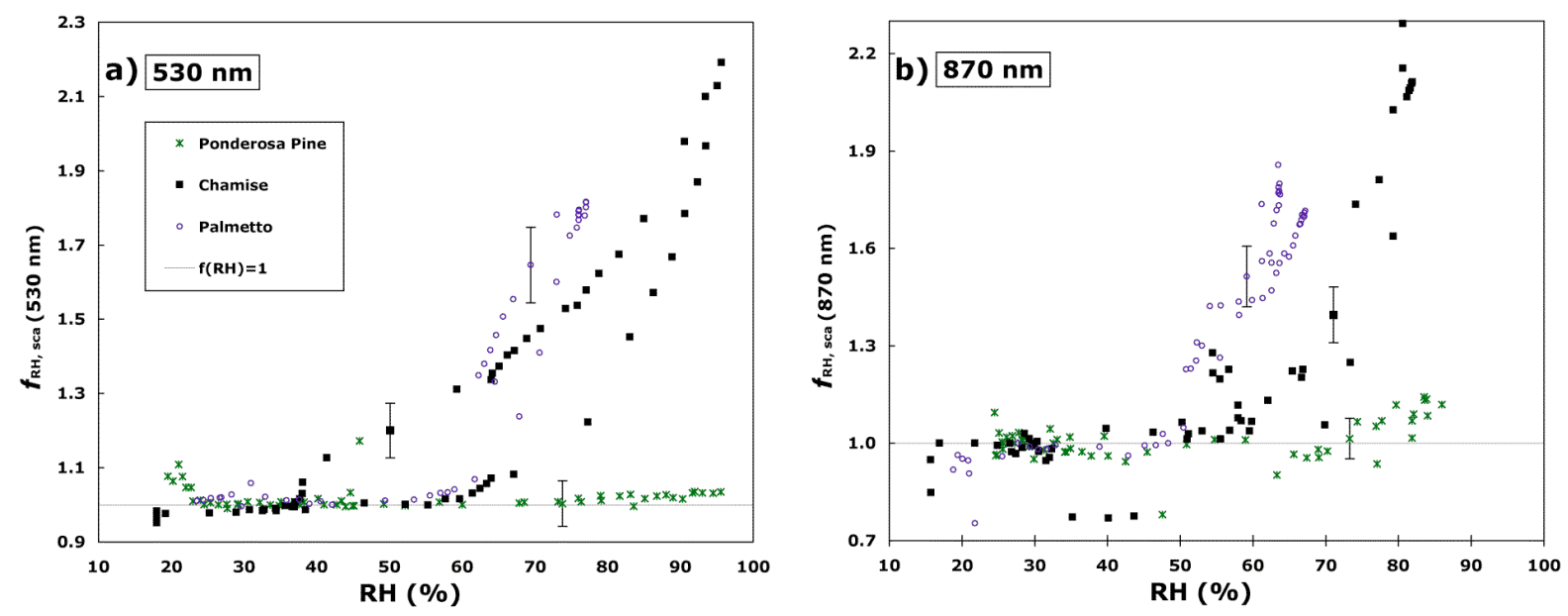

Fig. 2. Hygroscopic scattering growth factor as a function of RH. Growth factors were measured at (a) $530 \mathrm{~nm}$ and (b) $870 \mathrm{~nm}$. Scattering remains constant for ponderosa pine smoke but grows considerably with RH during chamise and palmetto burns.

some similarities between chamise and ponderosa pine combustion products. However, the inorganic inclusions present in chamise smoke make the two aerosols behave very differently under conditions of increasing humidity.

Images of combustion particles collected during palmetto burns are shown in Fig. 10, which includes the same sample area imaged with SE (panel a) and BSE (panel b) signals, along with characteristic X-ray spectra for the palmetto smoke particles in panel c. These particles are more compact and different in composition than other samples studied in this work. The sample is dominated by inorganic material, which is both internally and externally mixed with organic materials and soot particles. (Further evidence of some degree of external mixing within the aerosol is provided by the palmetto combustion particle HTDMA measurements, discussed near the end of the next section.) The apparent visibility of particles in the BSE image indicates their substantially non-carbonaceous content. EDX analysis of the four particles identified by number in the BSE image of Fig. 10b indicates that this sample is dominated by $\mathrm{KCl}$ and $\mathrm{NaCl}$ particles. The corresponding X-ray spectra are presented in Fig. 10c, and the results therein are in qualitative agreement with AMS measurements presented in Fig. 5c.

\subsection{HTDMA measurements}

Aerosol size change upon humidification also was measured by the HTDMA. The HTDMA system includes two DMAs in series. The polydisperse aerosol sample enters the system through a diffusion drier, reducing RH from ambient conditions to approximately $11 \%$, after which the first DMA selects a monodisperse particle size fraction by neutralizing the particles and separating them according to electrical mobility. The aerosol exiting the first DMA is humidified before it enters the second DMA. Coupled with a particle counter, this DMA is used to measure the size distribution of the humidified aerosol to obtain hygroscopic growth factors for the sample.

Apparent reductions in electrical mobility diameter were observed for chamise smoke particles with dry diameters greater than or equal to $200 \mathrm{~nm}$. The growth factor as a function of RH for dry particles with a mobility diameter of $100 \mathrm{~nm}$ is presented in Fig. 11a, while that for larger 200 and $300 \mathrm{~nm}$ diameter particles is depicted in Fig. 11b. Ponderosa pine smoke aerosol shows very little hygroscopic growth for either $100 \mathrm{~nm}$ or $200 \mathrm{~nm}$ diameter dry particles. The $100 \mathrm{~nm}$ diameter chamise smoke particles show modest increase in electrical mobility diameter with increasing RH. In contrast, the 200 and $300 \mathrm{~nm}$ diameter chamise particles first start to decrease in size at RH around 70 to $80 \%$, with larger reductions observed for larger dry particles. The electrical mobility diameter for an irregularly-shaped particle is larger than for a more compact particle composed of the same material (DeCarlo et al., 2004). Reduction in electrical mobility diameter measured by the HTDMA under high humidity conditions for larger chamise smoke aerosol particles is consistent with particle collapse observed in SEM images (Figs. 6 and 7). Particle collapse is predicted by fractal-like soot aggregate theory and has been widely described for humidified soot and other fractal-like particles, as discussed further in Sect. 4.2.

In reference to HTDMA measurements presented in Fig. 11a and b, growth factors are associated with particle electrical mobility diameter, $d$, and are calculated at a specific RH: $d(\mathrm{RH}) / d_{o}$, where $d_{o}$ is the "dry" diameter. Palmetto smoke particle electrical mobility diameter, depicted in Fig. 11a and b in shades of violet, increased rapidly for RH levels above $60 \%$. Unlike changing size distributions 

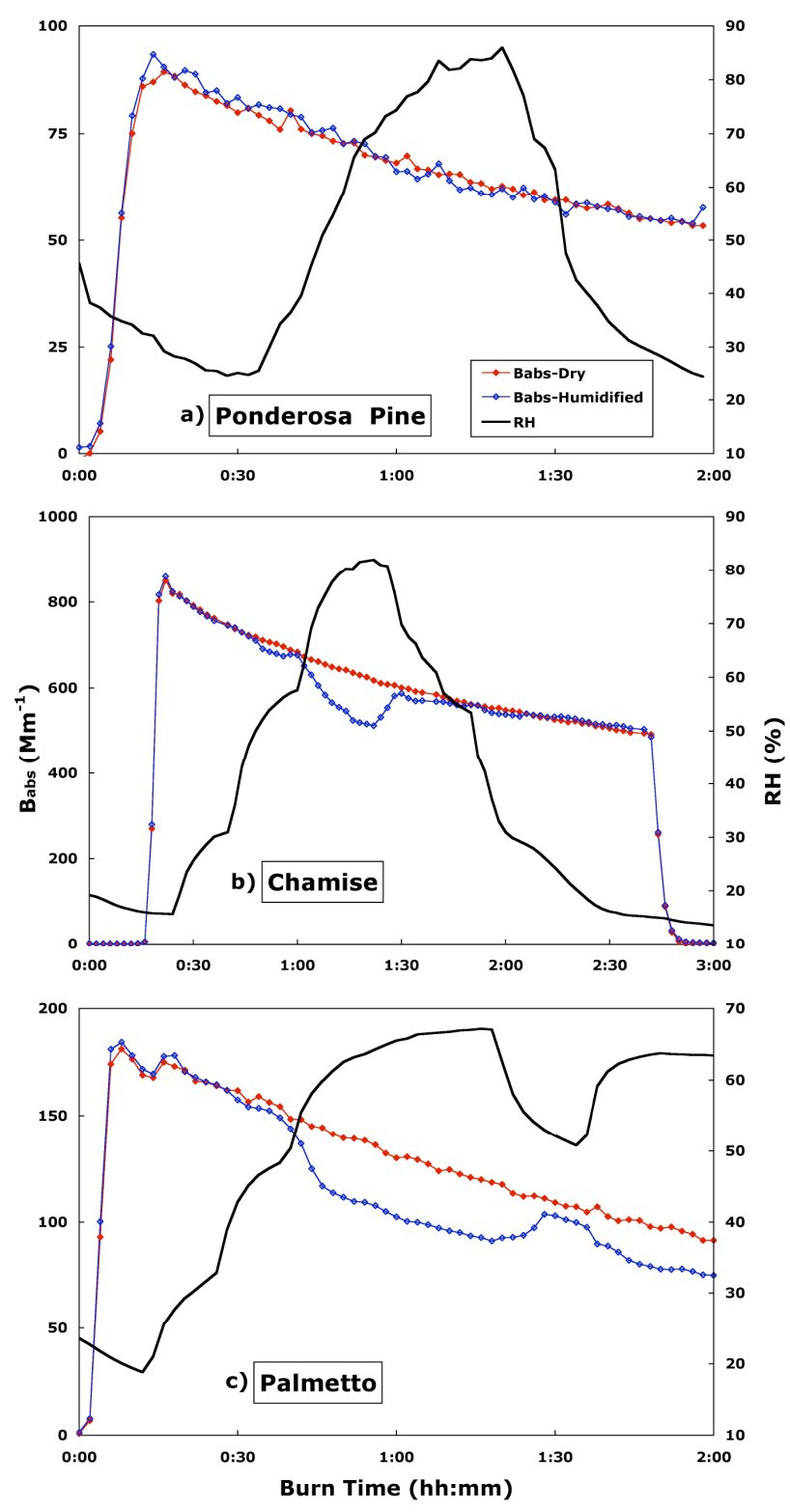

Fig. 3. Coefficients of absorption in $\mathrm{Mm}^{-1} \beta_{\text {abs }}$ measured by a photoacoustic instrument at $870 \mathrm{~nm}$ for a burn of (a) ponderosa pine, (b) chamise, and (c) palmetto fuel on two channels, including percent $\mathrm{RH}$ on the humidified channel.

for the pine and chamise smoke particles which remained monomodal, at $70 \% \mathrm{RH}$ and above the distribution for palmetto combustion products becomes bimodal. The separate growth of particles with increasing RH into "more" and "less" hygroscopic modes indicates some degree of external mixing and/or uneven internal mixing within the palmetto smoke aerosol (Carrico et al., 2005; Zhang et al., 1993). The center "volume weighted" ensemble growth factor, $\left(d / d_{o}\right)_{\text {ensemble, }}$, (plotted for palmetto in open circles) is

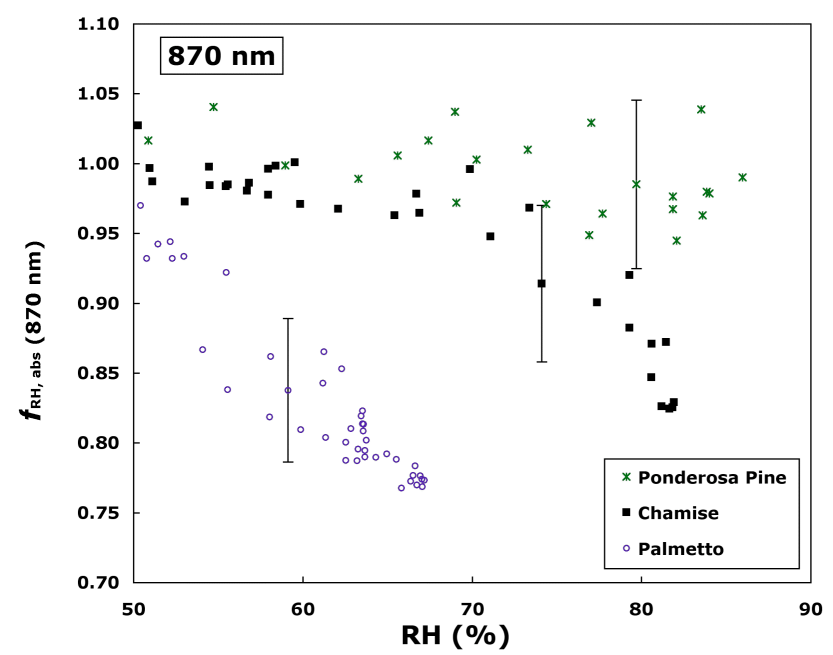

Fig. 4. Hygroscopic absorption growth factor as a function of RH. Growth factors are measured at $870 \mathrm{~nm}$ for the three fuels. Absorption by chamise and palmetto smoke decreases at high $\mathrm{RH}$.

calculated from the individual growth factors for modes 1 and 2 and the number fraction, $x$, in each mode:

$$
\left(d / d_{o}\right)_{\text {ensemble }}^{3}=x_{1}\left(d / d_{o}\right)_{1}^{3}+\left(1-x_{1}\right)\left(d / d_{o}\right)_{2}^{3}
$$

The subscripts denote the mode. This volume-weighted growth factor provides indication of whether the bimodal distribution is dominated by the "more" or "less" hygroscopic mode and provides a basis of comparison of the ensemble hygroscopicity to the monomodal cases described previously (Carrico et al., 2005).

\section{Discussion}

The morphology of the hydrophilic combustion particles of chamise and palmetto fuels can be modeled based on SEM images and composition measurements. The individual particles are composed of non-homogeneously mixed carbonaceous and inorganic materials. Chamise smoke particles are more fractal-like in nature, resembling the morphology typical for BC, diesel, or methane soot, while palmetto smoke particles are dominated by OC and inorganic species (Hopkins et al., 2007a). The particles are aggregates of the mixed materials, so that the exposed surface is composed of inorganic inclusions alongside carbonaceous species, as evident from the microscopy images of chamise combustion particles in Fig. 8 (Chakrabarty et al., 2006). These soluble inorganic salts on the particle surface will individually deliquesce, or absorb water from the surrounding air to form an aqueous solution, when RH surpasses a characteristic value. Water on the surface of the aerosol particles first pools in individual droplets until sufficient moisture has been taken up to allow cohesion of the drops to form an aqueous coating 


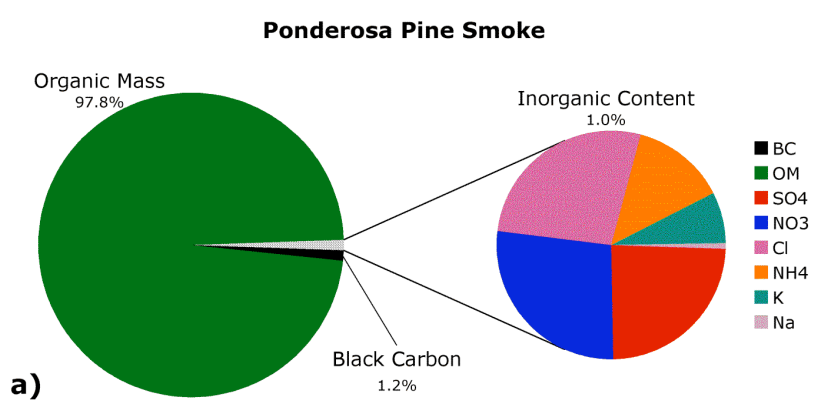

a)

Chamise Smoke
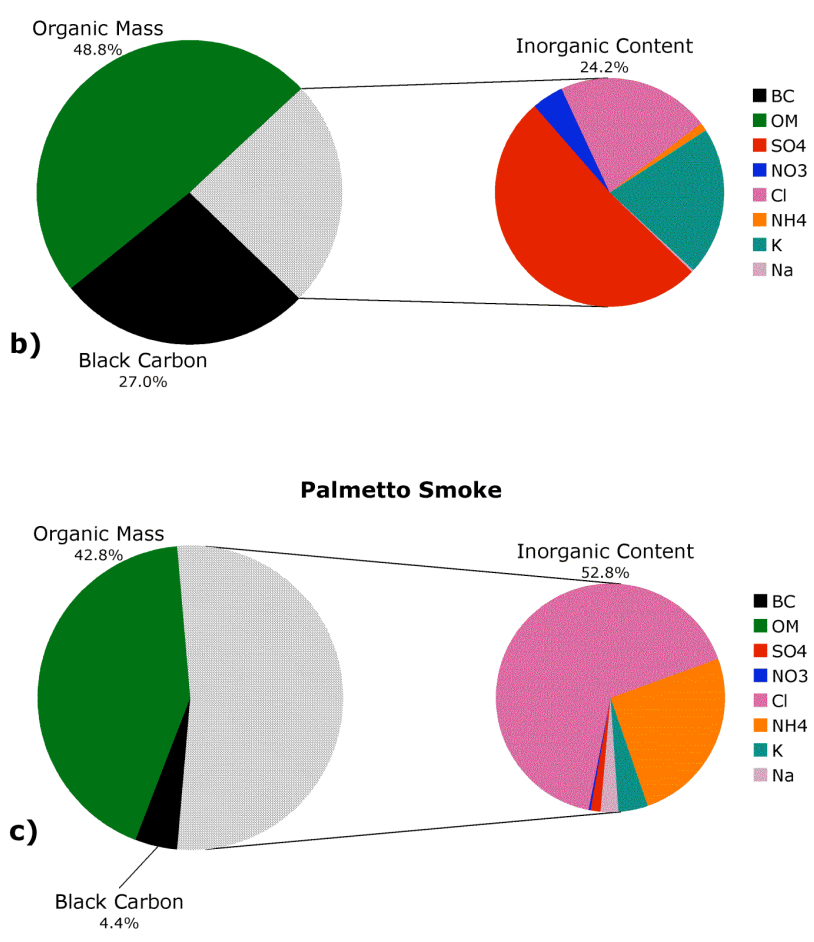

Fig. 5. Smoke particle mass composition for burns of (a) ponderosa pine, (b) chamise, and (c) palmetto.

surrounding the carbonaceous "core" particle (Ebert et al., 2002; Hand et al., 2005). In fractal-like aggregate particles, collapse may result and optical properties for humidified and collapsed particles are different from those of dry particles that have never been humidified. To provide a visual reference, a qualitative model of deliquescence, absorption, and collapse of a carbonaceous wood smoke particle containing salt inclusions is depicted in Fig. 12. For purpose of visualization, the collapsed particle depicted in panel d of Fig. 12 reveals a collapsed particle from which all moisture has been evaporated and both inorganic and organic matter have been thermally removed so that only BC material remains.

It is expected that the addition of a coating or shell on a soot core will enhance light scattering by the encapsulated particle (Fuller, 1993; Schnaiter et al., 2003). Particle size

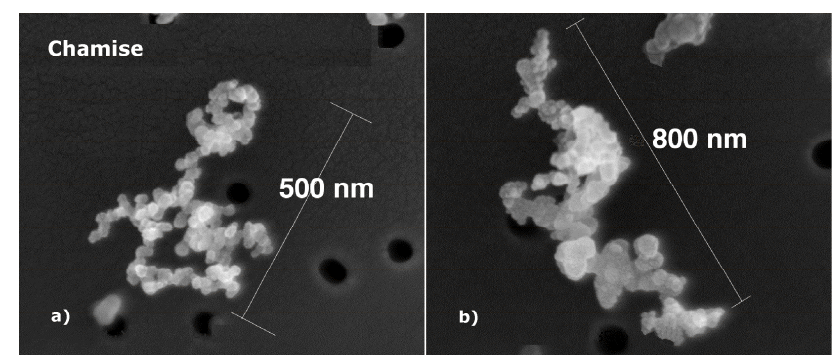

Fig. 6. Scanning electron microscope (SEM) images of (a) $500 \mathrm{~nm}$ and (b) $800 \mathrm{~nm}$ fractal-like soot chamise smoke particles sampled under ambient (dry) conditions without previous exposure to high RH. Individual monomers composing the fractal-like smoke particles are approximately $30 \mathrm{~nm}$ in diameter.

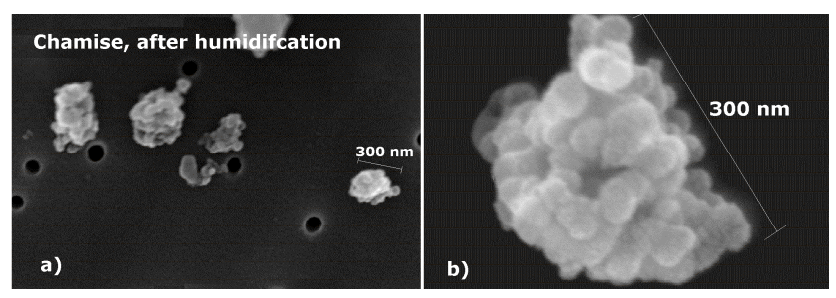

Fig. 7. Scanning electron microscope (SEM) images of collapsed (fractal dimension near 3) chamise smoke particles (a) sampled after humidification in excess of $80 \% \mathrm{RH}$. The diameter of each particle is approximately $300 \mathrm{~nm}$. The close up image of a single humidified chamise smoke particle (b) has been magnified four times.

increase due to the addition of a water shell with increasing RH causes the scattering enhancement, with the magnitude of enhancement dependent upon the size of the particle. The decrease in measured light absorption coefficients found here in conjunction with combustion particle coating by aqueous solution is, in contrast, unexpected. In general, enhancement of absorption cross sections with the presence of a non-absorbing coating around a carbonaceous core has been found in both experiment and theoretical calculations (Bond and Bergstrom, 2006; Bond et al., 2006; Fuller et al., 1999; Schnaiter et al., 2003). The coating has the effect of delivering more electromagnetic energy to the core for absorption than does a bare core. It is possible that the solution coating on hygroscopic combustion products of chamise and palmetto combustion particles is causing enhancement at the same time that competing effects produce an overall decrease in absorption coefficient. We propose two hypotheses to explain the measured reduction in light absorption.

\subsection{Hypotheses on reduction of absorption}

To explain the unexpected decrease in light absorption coefficients measured for combustion products with significant inorganic and OM components, two hypotheses are developed below. First, we propose that the collapse of fractal-like 

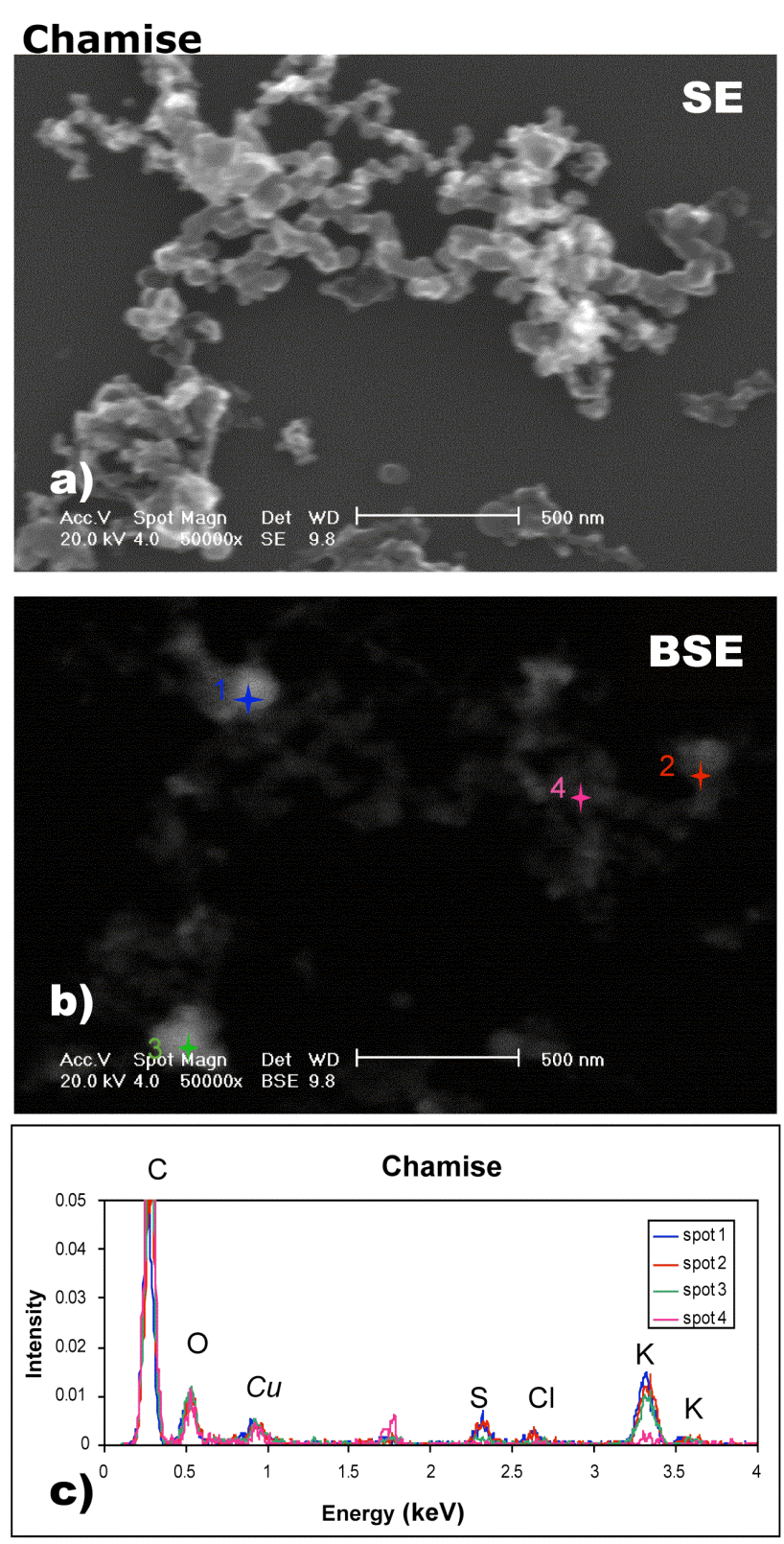

Fig. 8. Chamise SEM/EDX analysis. (a) SE and (b) BSE images of the same sample area of chamise combustion particles. The results of EDX analysis of the numbered bright areas in the BSE image are shown in (c). The aerosol is composed of typical soot chain particles along with inorganic inclusions that are both internally and externally mixed with the carbonaceous material. Highly carbonaceous materials are nearly invisible in BSE, whereas the inorganic inclusions show up as bright spots in the BSE image. (c) Characteristic X-ray spectra from manual EDX analysis of the inorganic inclusions present in chamise combustion particles. X-ray peaks are labeled by element. Intensity is in arbitrary units. The inorganic inclusions are mixed $\mathrm{KCl}$ and $\mathrm{K}_{2} \mathrm{SO}_{4} . \mathrm{Cu}$ is a substrate background, and the $\mathrm{C}$ and $\mathrm{O}$ intensities are mixed background and sample signals.

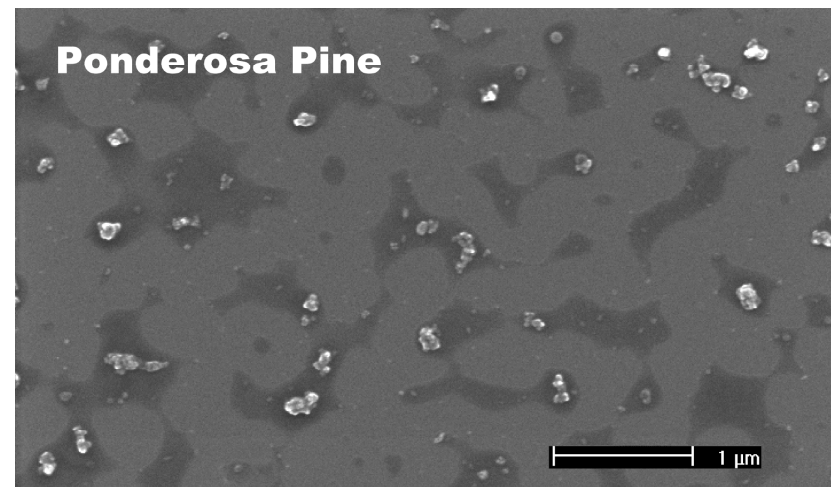

Fig. 9. SEM image of ponderosa pine combustion particles. Particles are composed of organic materials with soot inclusions. Soot is always inside of liquid/oily organic substances. Almost no elements other than $\mathrm{C}$ and $\mathrm{O}$ are present, with the exception of occasional trace amounts of $\mathrm{S}$ and $\mathrm{Cl}$.

aggregate particles, those of high $\mathrm{BC}$ content with morphology similar to diesel soot, causes a reduction in light absorption by the more compact, collapsed particles. For a highlybranched, fractal-like aggregate particle of low fractal dimension, the many small monomers (i.e., with circumference less than the wavelength of incident light) that compose the light absorbing carbon particle collectively contribute their individual mass to the light absorption of the entire particle. Therefore, absorption by the fractal particle is a volume effect with the entire particle volume contributing. However, when larger fractal particles collapse to form a more compact spherical structure, absorption becomes more of a surface area effect. Light absorption coefficients decrease with increasing (collapsed) particle diameter as only the surface (skin-depth) of the particle contributes to light absorption (Bond et al., 2006). This hypothesis is most relevant for larger particles, and those whose dry morphology demonstrates fractal-like geometry, such as chamise combustion particles.

A second explanation of decrease in measured light absorption with increasing RH comes from the photoacoustic measurements themselves and particle mass transfer in addition to heat transfer. In general, the photoacoustic signal is produced from heat generated by light absorption. The heat is transferred from the absorbing particle to the surrounding air, where it induces a pressure change which, once amplified by constructive interference within the photoacoustic resonator, is measured as an acoustic signal (Arnott et al., 1999). If, however, the aerosol is semivolatile, then changes in the photoacoustic signal resulting from mass transfer and latent heat must be considered, as discussed in Sect. 4.3.

\subsection{Particle collapse}

The collapse of fractal soot particles in conjunction with water condensation-evaporation is not a new phenomenon. 

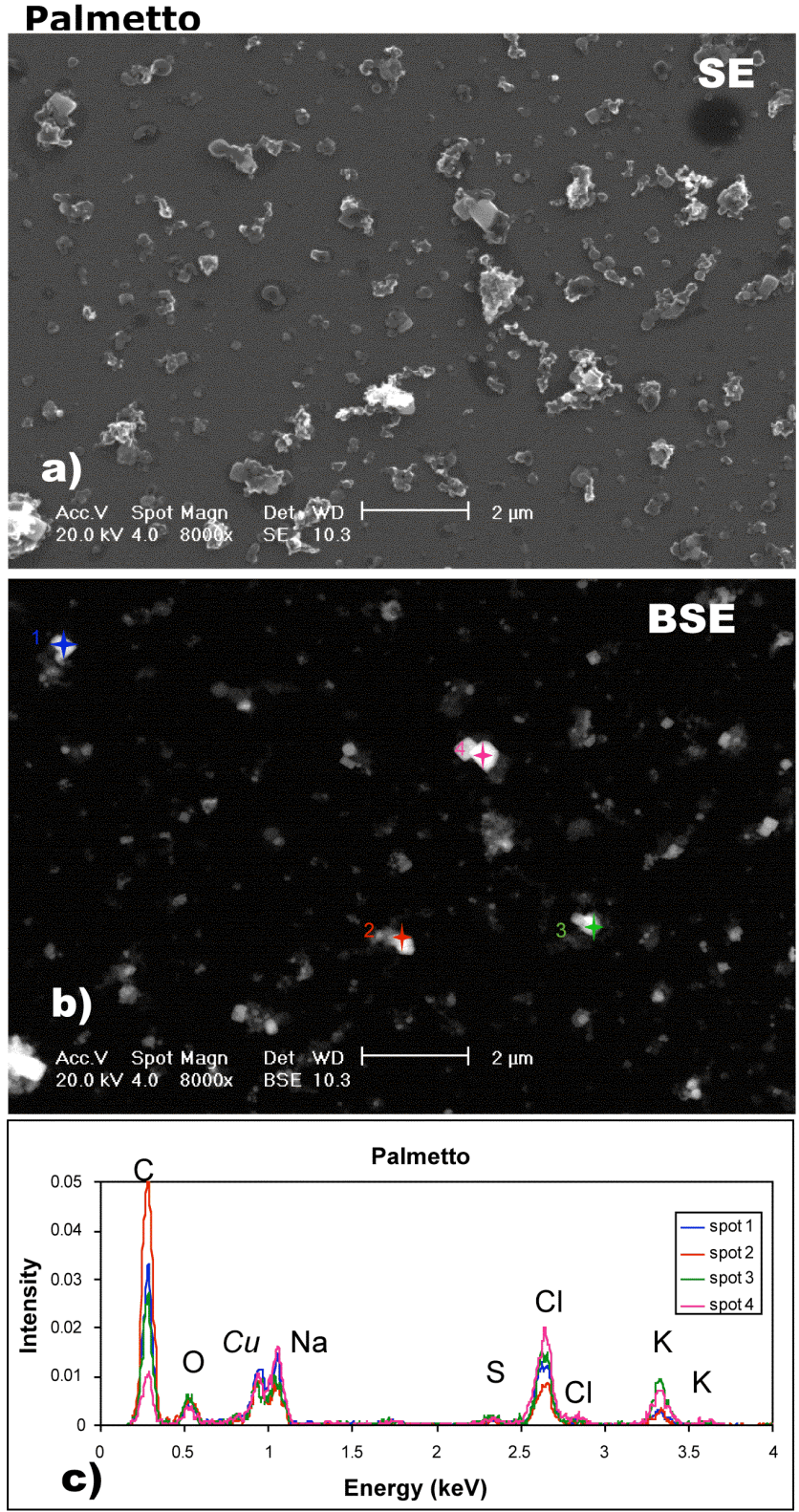

Fig. 10. Palmetto SEM/EDX analysis. (a) SE and (b) BSE images of the same sample area of palmetto combustion products. The results of EDX analysis of the numbered bright areas in the BSE image are shown in (c). The sample is dominated by inorganic salts, which are mixed with organic materials and $\mathrm{BC}$. The BSE signal is largely blind for OC and BC. Similarities in the two images, namely the presence of most particles visible in the SE image as bright spots in the BSE image, indicate the substantially noncarbonaceous content of the palmetto smoke. (c) Characteristic Xray spectra from manual EDX analysis of palmetto combustion particles. X-ray peaks are labeled by element. Intensity is in arbitrary units. The sample is dominated by $\mathrm{KCl}$ and $\mathrm{NaCl}$. $\mathrm{Cu}$ is a substrate background.
Reports and images of particle collapse are commonly found in the literature (Chamberlain et al., 1975; Colbeck et al., 1997; Hallett et al., 1989; Huang et al., 1994; Jimenez et al., 2003; Mikhailov et al., 2006; Nelson, 1989; Weingartner et al., 1995; Weingartner et al., 1997; Zuberi et al., 2005) dating as far back as 1975. In a study of uptake of lead by inhalation of motor exhaust, Chamberlain et al. (1975) observed a more "homogenous" structure of previously chain aggregate carbonaceous material after it was exhaled from a humid human lung. It was reported that this was similar to the effect on chain aggregate-type aerosol that was drawn through a humidifier. Chamberlain et al. (1975) postulated that the chain aggregate particle collapses in wet air due to the discharge of electrostatic forces. A later explanation cited by Hallett et al. (1989) and Weingartner et al. $(1995,1997)$ is that condensation of water in small angle cavities of the branched structure leads to capillary forces that collapse the asymmetric particle.

\subsubsection{Experimental support for absorption reduction}

Recently, collapse of fractal soot particles under high $\mathrm{RH}$ was observed by Mikhailov et al. (2006) in their experimental study of soot-water drop optical properties. Hydrophilic soot (HLS) and highly hydrophilic soot (HHLS) particles were generated by condensing glutaric acid vapor in different quantities on fresh (hydrophobic) acetylene soot, and the structural and optical properties of the particles were observed at $10 \% \mathrm{RH}$ and $100 \% \mathrm{RH}$. Glutaric acid is an organic compound. One atmospheric source of the acid is direct emission as a product of biomass burning. Mikhailov et al. (2006) found that the HLS and HHLS particles collapsed into globules after wetting due to growth of water droplets on the soot surface and subsequent evaporation resulting in surface tension forces which cause the branched soot structures to collapse into a dense, spherical structure. Soot collapse was characterized by a shift of the particle to larger fractal dimensions and smaller size spectrum.

Also reported by Mikhailov et al. (2006) was an increase in light scattering by the soot-water-drop agglomerates. Higher scattering cross sections and single scattering albedo values were measured for hydrophilic soot particles at RH of $100 \%$ compared to $10 \%$. The researchers reported a scattering enhancement factor (of 34 \pm 5 ) associated with the scattering cross section of highly hydrophilic soot compared to that of hydrophobic soot (HBS) particles (at $\mathrm{RH}=100 \%$ ). Concurrently, experimental measurements of volumetric absorption coefficients are systematically lower for HLS particles at $100 \% \mathrm{RH}$ compared to $10 \% \mathrm{RH}$ measurements for soot mass concentrations greater than $0.010 \mathrm{~g} \mathrm{~m}^{3}$. When comparing HHLS particles to HBS particles, Mikhailov et al. (2006) conclude that a nonabsorbing shell around the soot core, such as glutaric acid used in their experiment, leads to an increase in absorption, as evidenced by the reported absorption enhancement factor of $3.5 \pm 1$. However, there appears to be 

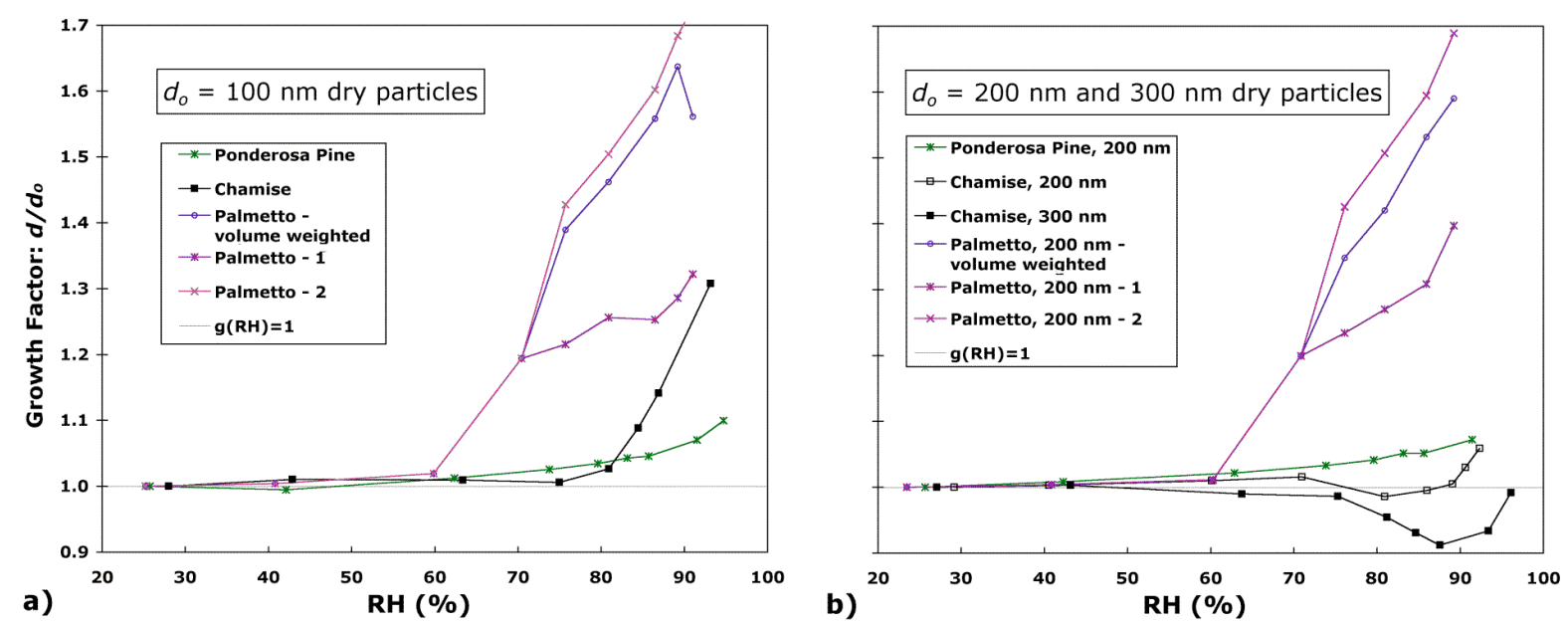

Fig. 11. Growth factor fraction: $d / d_{o}$ Hygroscopic growth of particle size (electrical mobility diameter) for (a) smaller and (b) larger smoke particles as a function of increasing relative humidity. Growth factor is the ratio of particle electrical mobility diameter, $d$, to dry diameter, $d_{o}$.

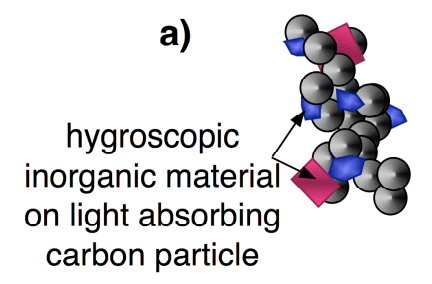

c)

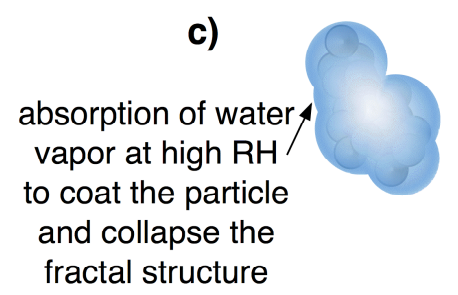

Fig. 12. Model of combustion product morphology for a carbonaceous particle with inorganic inclusions under increasing $\mathrm{RH}$ conditions.

experimental evidence of some degree of reduction in light absorption by Mikhailov et al. (2006) at high RH, in addition to particle collapse, in reported results comparing a single aerosol type, HLS, at two different RH conditions. Experimental measurements of volumetric absorption coefficients are systematically lower for HLS particles at $100 \%$ RH compared to $10 \% \mathrm{RH}$ measurements for soot mass concentrations greater than $0.010 \mathrm{~g} \mathrm{~m}^{3}$, as evidenced by comparison of the blue triangles in reprinted Fig. 13 (Mikhailov et al., 2006).

Environmental scanning electron microscopy (ESEM) also has been employed to provide real time visual observation of the hygroscopic transformations of individual soot particles. Morphological and structural changes are reported

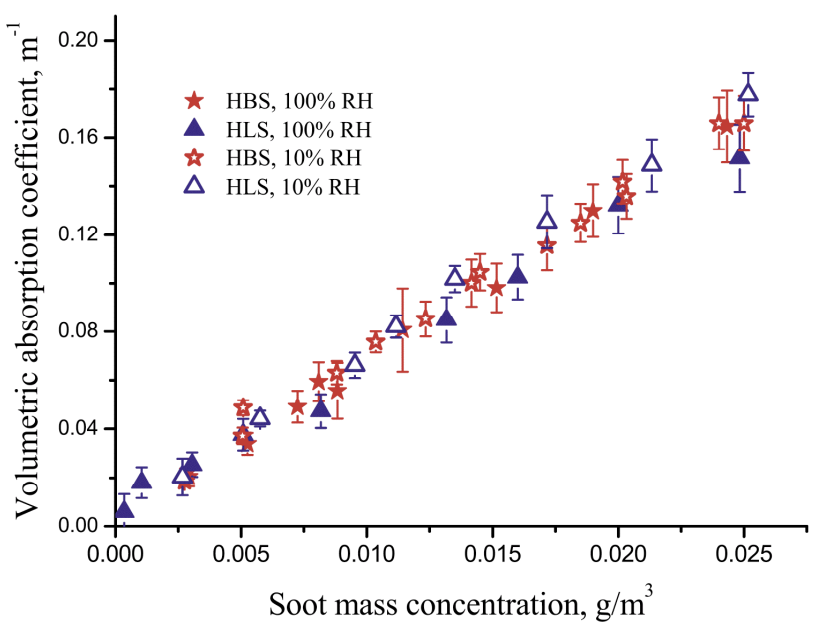

Fig. 13. By Mikhailov et al. (2006). Volumetric absorption coefficients of hydrophobic (HBS: red) and hydrophilic (HLS: blue) soot as a function of volume mass concentration. A comparison of likecolored open versus solid symbols reveals differences between the aerosols at $\mathrm{RH}=10 \%$ and $\mathrm{RH}=100 \%$, respectively. While no difference can be detected in levels measured for the two HBS samples, light absorption coefficients for HLS at $100 \% \mathrm{RH}$ are systematically lower than those measured under dry conditions.

for soot particles that have undergone activation (unconstrained water uptake) at critical supersaturation followed by dehydration or evaporation (Ebert et al., 2002; Zuberi et al., 2005). The dried particle appears more compact and has a less porous structure after hydration. Additionally, particle shrinkage results from collapse of the internal microstructure (Zuberi et al., 2005). 

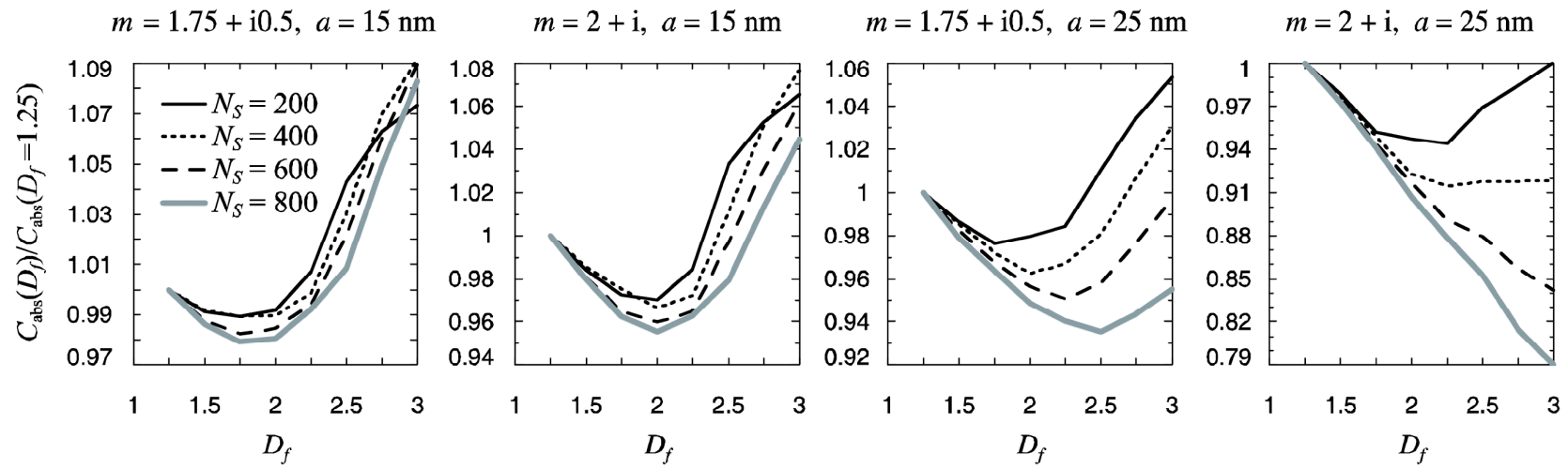

Fig. 14. By Liu et al. (2008). Absorption optical cross sections as a function of the fractal dimension, $D$ (presented here as $D_{f}$ ), normalized by the corresponding value for $D=1.25$. The results are calculated at different values of refractive index, (presented here as $m$ ), and monomer radius, $a$, and each curve depicts the results computed for fractals composed of a particular number of monomers, $N_{s}$. Although many of the curves have minimum points, only for particles of sufficient size and refractive index do absorption cross sections decrease significantly as the particle becomes more compact ( $D$ increases).

\subsubsection{Theoretical support}

In addition to experimental observations, there exist theoretical predictions relating to changes in scattering and absorption with soot particle collapse. Using the superposition $T$-matrix method to compute optical cross sections for fractal-like soot aggregates of varying morphology (Liu and Mishchenko, 2005), it was found that mass-specific scattering and extinction increased with increasing fractal dimension $D$ and fractal prefactor $k_{o}$. In contrast, that work reported a slight decrease in mass-specific absorption for soot clusters with the larger of the investigated refractive index values $(2+i)$ as a function of $D$ and $k_{o}$. Recall that $D$ is related to particle compactness, with larger values associated with denser more spherical particle morphology, and to a lesser extent the same holds true for $k_{o}$. Further theoretical study of the radiative properties of fractal soot aggregates using this method revealed a systematic reduction in light absorption with increasing $D$ for particles of sufficient size (large number of monomers and monomer radius) and refractive index. Reprinted Fig. 14 presents these results (Liu et al., 2008) of decreased absorption cross sections for compact fractal soot aggregates $(D=3)$ with increasing particle size. Particle size is indicated by number of monomers composing the fractal aggregate. The normalized absorption cross section is calculated for different combinations of two particle properties: refractive index and monomer radius.

It is apparent in the theoretical calculations presented in Fig. 14 that for sufficiently large particles (monomer number greater than 400 and monomer radius of $25 \mathrm{~nm}$ ) with high refractive index $(2+i)$, a 10 to $20 \%$ reduction in light absorption is expected. However, the size and optical properties of the combustion particles are more likely to correspond to the lower refractive index value and smaller monomer size shown in the first box of Fig. 14. Reduction in light absorption cross section due to particle collapse is additionally more probable for combustion particles with high $\mathrm{BC}$ content and a fractal-aggregate morphology, such as chamise combustion particles. It is not known whether palmetto combustion products, which are high in OC and inorganic content, collapse under high RH conditions.

\subsection{Mass transfer}

When operating the photoacoustic instrument under conditions of high relative humidity (e.g., $\mathrm{RH}>60 \%$ ) or for measuring the light absorption of volatile aerosols, the mass transfer effects of evaporation and condensation must be taken into account. The photoacoustic signal is produced by heat transfer from particles that have absorbed radiation, but mass transfer also can generate a signal though with a different efficiency than heat transfer due to the expenditure of energy in latent heat that does not contribute to the acoustic excitation, and/or energy can be channeled into latent heat without signal production. For example, consider light absorption by a water droplet or the present case of light absorption by a soot particle that has experienced water uptake under high RH conditions. If the droplet or particle is illuminated by radiation at a wavelength of strong absorption by the core, the laser light will be absorbed. Not only will this absorbed radiation heat the particle, but some power will be transferred into latent heat causing evaporation to occur and add additional water vapor to the surrounding air. These additional water vapor molecules will contribute to the acoustic signal. An illustrative analogy is the reduction of photoacoustic signal observed when gaseous $\mathrm{NO}_{2}$ is illuminated by 
radiation of low enough wavelength to photodissociate the molecules. In this case, some energy will be absorbed by the $\mathrm{NO}_{2}$ and transferred to the surrounding air, but some energy will go into $\mathrm{NO}_{2}$ photodissociation (Arnott et al., 2003; Raspet et al., 2003).

A model has been developed for this application that builds on previous work by Arnott et al. (2003) and Raspet et al. (2003) in examining the effects of relative humidity on photoacoustic measurements of aerosol light absorption. The expression used to calculate absorption coefficient $\beta_{\mathrm{abs}}$ is the photoacoustic equation:

$\beta_{\mathrm{abs}}=\frac{P_{m}}{P_{L}} \frac{\pi^{2} f_{o} A_{\text {res }}}{Q S}$,

where $\beta_{\mathrm{abs}}$ is proportional to the measured microphone power at resonance frequency, $P_{m}\left(f=f_{o}\right)$, divided by laser power at resonance, $P_{L}\left(f=f_{o}\right)$. Fourier transformations of both microphone response and laser power measurement transform the time domain signals into complex functions in the frequency domain for determination of microphone and laser power values at the resonance frequency, $f_{o}$. Light absorption is also a function of resonator cross sectional area, $A_{\text {res }}$; resonator quality factor, $Q$; and resonance frequency. Evaporation and condensation are accounted for in the dimensionless photoacoustic source, $S$, which includes terms for both mass transfer, $m$, and heat transfer, $h$ :

$S=m c^{2}+(\gamma-1) h$,

where

$m=\frac{E}{1-i T+L E}$,

and

$h=\frac{1}{1-i T+L E}$.

$L$ is the latent heat of vaporization for liquid water in Joules per kilogram $(\mathrm{J} / \mathrm{kg})$. Additionally, $\gamma$ is the ratio of isobaric and isochoric specific heats for air. For dry air, $\gamma=1.4$; in general, $\gamma$ is dependent upon RH. $E$ is associated with evaporation and condensation:

$E=\frac{\rho_{w} \rho_{o}}{\rho_{d}} \frac{D_{m}}{\kappa T_{o}}\left(\frac{L m_{w}}{R T_{o}}-1\right)$,

where $\rho_{w}, \rho_{d}$, and $\rho_{o}$ are the density of water vapor, density of dry air, and total density of air with water vapor, respectively. The thermal conductivity of the sample is given by $\kappa$; $D_{m}$ is the mass diffusion coefficient; and $m_{w}$ is the molecular weight of water vapor. $R$ is the universal gas constant, and $T_{o}$ is the ambient temperature. $T$ is a dimensionless term associated with the thermal relaxation time, $\tau$, it takes for an illuminated particle to transfer absorbed heat to the surrounding air. $T$ can be expressed as

$T=\omega \frac{c_{p} \rho r^{2}}{3 \kappa} \equiv \omega \tau$, where $\omega=2 \pi f_{o}$ is the radian frequency in radians per second, $c_{p}$ is the specific heat capacity of the particle, $\rho$ is the particle density, and $r$ is particle radius. $S$ is generally evaluated with $T=0$. Assuming $T \rightarrow 0$ implies that the heat transfer time of the particle is much less than the acoustic period of resonant operation. A non-zero value of $T$ would be apparent in operation as a phase shift between the oscillating power of the laser beam and the microphone signal. No phase difference was detectable in the reported photoacoustic measurements.

Therefore, the photoacoustic source term for absorption by a volatile particle can be expressed as

$S=\frac{E c^{2}+(\gamma-1)}{1-i T+L E}$.

When mass transfer can be neglected, that is no evaporation or condensation occurs, $E$ goes to zero and the source term reduces to $S_{\mathrm{dry}}$ :

$S_{\text {dry }}=\frac{(\gamma-1)}{1-i T}$.

The source term used under dry conditions in calculating $\beta_{\mathrm{abs}}$ is $S=S_{\text {dry }}$, with $T=0$ (Arnott et al., 2003).

The theory developed to model the photoacoustic signal under the influence of evaporation and condensation assumes a particle partially covered with a liquid with the vapor pressure of water. Changes in absorption coefficient due to coating enhancement or particle morphology (such as particle collapse) under changing RH conditions are not considered by the theory, which simply provides insight into the effects of heat and mass transfer on photoacoustic signal generation. Calculation of useful parameters to determine $E$ and photoacoustic source term $S$ was carried out using the code developed by Raspet et al. (1999). The code calculates the transport and thermodynamic properties of dry and moist air given inputs including molecular properties of dry air and water vapor (i.e., molecular weight and degrees freedom), air temperature, and latent heat. We present a model initialized with this code for the measured photoacoustic light absorption coefficient values, taking into account evaporation and condensation effects.

The temperature value used was the average experimental temperature and was specific to each burn. Another important parameter is the latent heat of vaporization of water, a temperature-dependent value. The formula used includes temperature in units $\mathrm{K}$ and the latent heat of vaporization is given in $\mathrm{J} / \mathrm{kg}$ :

$L\left(T_{o}\right)=L_{o}-3041\left(T_{o}-273.1\right)$,

where $L_{o}=2500000 \mathrm{~J} \mathrm{~kg}$. The value of $L$ is only expected to be a significant function of salt solution concentration at the point of saturation; when the solution is unsaturated it remains nearly constant (Lunnon, 1913). Presumably, the salt solution is at saturation at the point of deliquescence. The latent heat is likely slightly lower at this point, which would 
cause a slight increase in $\beta_{\text {abs. }}$. The measured absorption coefficient would decrease with increasing water content. A slight deviation in $\beta_{\text {abs }}$ of this kind is not observed experimentally. For our calculations, $L$ is not treated as a function of solution concentration.

The theory assumes water vapor is saturated for the particle salt solution at given RH. To account for the fact that humidity conditions during each burn were changing, the series of measured RH values were included in the code in the determination of sample vapor pressure. Vapor pressure, in turn, was used to calculate additional thermodynamic parameters leading to evaluation of $E$ and $S$.

It is likely, as depicted in Fig. 12, that the entire surface of the carbonaceous particle is not covered with a water (or solution) shell, but rather initially only a fraction of the surface participates in deliquescence. This liquid surface coverage fraction, defined here as $\alpha$, is related to the fraction of exposed inorganic material on the surface of the particle and is expected to rise with increasing humidity. (Assuming a homogenous mixture of carbonaceous and inorganic materials, $\alpha$ could be roughly estimated as the mass fraction of inorganic material to total mass.) In the proposed model, the interaction of the instrument with the particle is such that a fraction of the light-absorbing mass is subject to mass transfer considerations, and therefore $S(\mathrm{RH})$ must be used in the determination of $\beta_{\text {abs }}$, while $S$ will reduce to $S_{\text {dry }}$ in calculating $\beta_{\text {abs }}$ for the remaining fraction. When, as usual, $S_{\text {dry }}$ is used, the photoacoustically measured light absorption coefficient under high RH conditions, $\beta_{\mathrm{abs}}^{\text {measured }}(\mathrm{RH})$, is less than the true value which takes into account evaporation and condensation, $\beta_{\mathrm{abs}}^{\text {true }}(\mathrm{RH})$. We define, and soon derive, a correction source function, $F$. The measured value divided by the correction source term gives the true value:

$\beta_{\mathrm{abs}}^{\text {true }}(\mathrm{RH})=\beta_{\mathrm{abs}}^{\text {measured }}(\mathrm{RH}) / F$.

The model for $F$ is as follows:

$F=\frac{\alpha S+(1-\alpha) S_{\text {dry }}}{S_{\text {dry }}}$.

In general, the true light absorption coefficient is equal to that measured by the dry/ambient channel less any reduction due to the effects of collapse, plus enhancement due to particle coating:

$\beta_{\mathrm{abs}}^{\text {true }}(\mathrm{RH})=\beta_{\mathrm{abs}}^{\text {measured }}(\mathrm{dry}) \times a_{\text {collapse }} \times A_{\text {coating. }}$.

Enhancement and reduction effects due to coating and collapse are represented by $A_{\text {coating }}$ and $a_{\text {collapse, }}$, respectively, such that $A_{\text {coating }}$ is expected to be greater than 1 and $a_{\text {collapse }}$ is expected to be less than 1. Because we do not know the magnitudes of the light absorption enhancement and reduction factors, the product of $a_{\text {collapse }}$ and $A_{\text {coating }}$ is taken to be 1 in this model. Then,

$F=\frac{\beta_{\mathrm{abs}}^{\text {measured }}(\mathrm{RH})}{\beta_{\mathrm{abs}}^{\text {measured }}(\text { dry })}=f_{\mathrm{RH}}$, as $f_{\mathrm{RH}}$ is defined in Eq. (2). Therefore, the surface fraction covered by liquid can be determined by

$\alpha=\frac{f_{\mathrm{RH}}}{\left(S / S_{\mathrm{dry}}-1\right)}$,

using $S$ as calculated by the mass transfer theory, and $f_{\mathrm{RH}}$ calculated using measured $\beta_{\text {abs }}$ values from the humidified and ambient (dry) channels.

Surface coverage by liquid, $\alpha$, is presented in Fig. 15 as a function of measured RH for each of the three burns. This estimation of deliquescence and fraction of particle coating by solution was found using the theoretical model for photoacoustic measurements involving evaporation and condensation along with actual photoacoustic measurements of aerosol absorption on the "dry" and "wet" channels. The model predicts a reduction in measured light absorption cross section, and Fig. 15 is the liquid surface coverage implied by the reduction. The horizontal lines relating to each combustion product depict the mass fraction of inorganic material to total mass, or surface coverage implied by a homogeneous mixture of particle components (BC, OC, and inorganic salts). The theoretically calculated values are shown in Fig. 15 as points, and the thick lines are polynomial fits included for visualization. The polynomial fit is included simply as a guide to the eye and is not meant to convey functional dependence. A hand-drawn curve representing the data also would suffice for our purpose. The spread in the points is attributable to inaccuracies in the RH measurement on the photoacoustic instrument. A particle filter on the sample line prior to the RH sensor is unable to equilibrate instantaneously, so that a lag exists between actual humidity conditions and RH measurements. The surface coverage for ponderosa pine combustion products remains scattered around zero with increasing humidity, whereas that for chamise and palmetto begins to increase with increasing $\mathrm{RH}$ at what is presumably the deliquescence point for the inorganic salts on each aerosol. As different salts will have different deliquescence points, the shape of the "aqueous solution fraction" curves may be influenced by multiple salts responding at different RH levels.

\section{Conclusions}

Under increasing RH conditions, biomass combustion aerosols from three different sources sampled during the 2006 FLAME-1 campaign experienced slight or strong water uptake, which in turn affected aerosol optical properties. The amount of moisture absorbed by particles from the combustion of a particular fuel type corresponds to the morphology and chemical composition of the fuel and smoke. Ponderosa pine smoke particles, for example, which are dominated by OC, experienced very little liquid uptake and therefore very little change in light scattering and absorption coefficients, even at RH levels above $85 \%$. In contrast, particles from the combustion of chamise and palmetto, which in addition to 


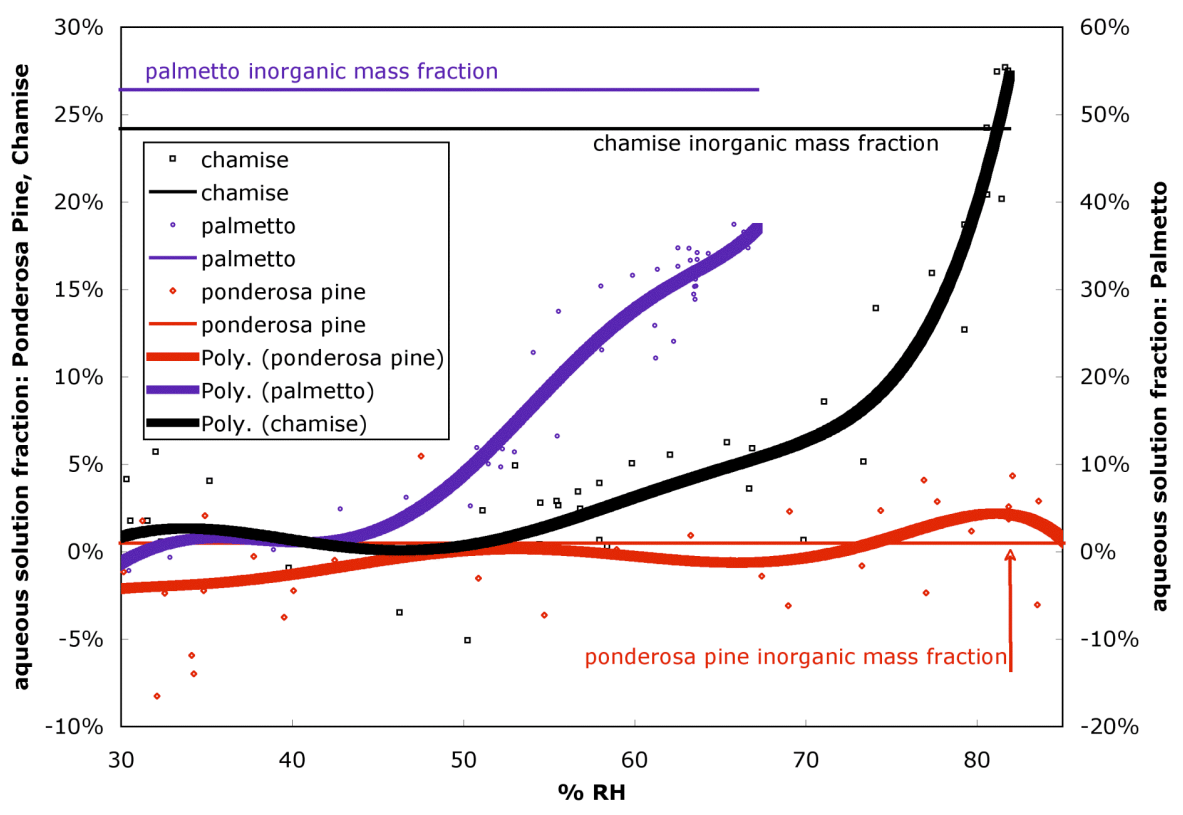

Fig. 15. Evaporation/condensation-implied surface coverage fraction. Surface coverage of liquid solution for each combustion product calculated using a model for photoacoustic absorption coefficient signals which includes evaporation and condensation and implied by measured values of $\beta_{\mathrm{abs}}$ under both ambient and high RH conditions.

$\mathrm{OC}$ and $\mathrm{BC}$ include hygroscopic inorganic materials, experience notable changes in their optical properties. The inorganic salts deliquesce at characteristic RH values. It is expected that liquid coverage begins with a fraction of the surface and increases with water uptake and humidity.

The increase in measured light scattering coefficients for combustion particles with some degree of hygroscopicity, such as chamise and palmetto combustion particles, is predicted by particle shell models and experiments. However, the decrease in measured light absorption cross sections with increasing $\mathrm{RH}$ values is an unexpected result. It is possible that competing effects exist, and salt on the particle surface and then salt solution following deliquescence is providing light absorption enhancement at the same time that particle collapse and the effects of evaporation and condensation are reducing the photoacoustic signal. Measurable decrease in light absorption cross section due to particle collapse is most relevant for combustion particles with high BC content, fractal-like aggregate morphology, and with inorganic constituents present for hygroscopicity. For the combustion products discussed here, evidence of particle collapse was only seen for chamise smoke. Palmetto smoke particles are possibly already collapsed without the addition of high humidity due to the high content of OC and inorganic material seen in these particles. The more important effects of evaporation and condensation on the measured photoacoustic signals likely provide the bulk of light absorption coefficient reduction. The observed 10 to 20 percent reduction in the measured photoacoustic value compared with the true light absorption cross section is well within the expected mass transfer effect predicted for a substantial liquid coating on a light absorbing particle.

Three mechanisms altering light absorption measurements were discussed. Particle collapse within typical particle size range gives a decrease in absorption by as much as $6 \%$, but also shows an increase as fractal dimension approaches three. Modeling efforts from the literature indicate absorption enhancements of around $50 \%$ for BC cores with weakly absorbing coatings. Particle morphological differences limit the conclusions that can be made from coated sphere theory. Mass transfer without correction leads to as much as $20 \%$ reduction of absorption from the real value for aerosol with large inorganic content. Our tentative conclusion is that mass transfer associated with photoacoustic measurement of aerosol light absorption is the mechanism that best explains the observed reduction of aerosol light absorption with RH.

We recommend future studies to separate the effects of collapse and inorganic coating from the mass transfer effects on the photoacoustic signal. Light absorption coefficients of chamise combustion products should first be measured in ambient/dry condition. The sample could then be subject to high humidity to collapse the particles followed by aerosol drying of the same sample before light absorption values are measured once more. Additionally, a volatility measurement is recommended, in which light absorption is measured for combustion particle samples after heating and subsequent 
evaporation of any organic matter or inorganic materials, as described by Huffman et al. (2009). Then the optical properties of solely the soot core could be photoacoustically analyzed. It may be possible to use these sorts of experiments for photoacoustically evaluating the mass accommodation coefficient of an aerosol as discussed in Murphy (2009) if sizeselective methods, as in Slowik et al. (2007), are used. Particle size effects on the photoaoustic signal due to evaporation appear to be dramatic (Murphy, 2009). In a humid environment, coating and collapse effects (which would affect any absorption measurement), as well as possible instrumental artifacts (specific to photoacoustics) affect the measured optical properties of biomass smoke aerosols at varying levels due to particle composition and morphology. Photoacoustic measurements of dry and moist aerosol can be used to estimate the fraction of surface covered by salt solution.

Acknowledgements. This research was supported in part by grants 0552230 and 0511769 from the National Science Foundation (NSF) to the Desert Research Institute and the University of Nevada, Reno, and in part by the Desert Research Institute through the Applied Research Initiative of the State of Nevada. This work also was supported by the Atmospheric Science Program of the US Department of Energy, Office of Biological and Environmental Research (OBER) and by the Joint Fire Science Program (JFSP) funding FLAME through the US National Park Service (NPS) project \#J8R07060005. JLJ, JAH, and IMU were supported by NSF (ATM-0513116) and EPA STAR (R833747). LL and MIM were supported by the NASA Radiation Sciences Program and the NASA Glory Mission project. The authors gratefully acknowledge the staff at the USDA/USFS Fire Sciences Laboratory, along with Wei-Min Hao and Jeffery L. Collett Jr., who participated in organizing the FLAME project. Additionally, the authors acknowledge Grizelle Gonzalez, USDA Forest Service: Sabana Field Research Station, Puerto Rico, Kevin Robertson, Tall Timbers Research Station, Tallahassee, FL, Joey Chong and David Weise, USDA Forest Service: Riverside Fire Laboratory and Robert Olson, Utah Air Quality for their contributions of biomass fuels. Preliminary AMS analysis was aided by Jesse Kroll, Massachusetts Institute of Technology. The SEM/EDX particle analysis was performed in the Environmental Molecular Sciences Laboratory, a national scientific user facility sponsored by the Department of Energy's Office of Biological and Environmental Research at Pacific Northwest National Laboratory. PNNL is operated by the US Department of Energy by Battelle Memorial Institute under contract DE-AC06-76RL0.

Edited by: V. F. McNeill

\section{References}

Abu-Rahmah, A., Arnott, W. P., and Moosmüller, H.: Integrating nephelometer with a low truncation angle and an extended calibration scheme, Meas. Sci. Technol., 17, 1723-1732, 2006.

Arnott, W. P., Moosmüller, H., Rogers, C. F., Jin, T., and Bruch, R.: Photoacoustic spectrometer for measuring light absorption by aerosols: Instrument description, Atmos. Environ., 33, 28452852, 1999.
Arnott, W. P., Moosmüller, H., Sheridan, P. J., Ogren, J. A., Raspet, R., Slaton, W. V., Hand, J. L., Kreidenweis, S. M., and Collett, J. L.: Photoacoustic and filter-based ambient aerosol light absorption measurements: Instrument comparisons and the role of relative humidity, J. Geophys. Res., 108(D1), 4034, doi:10.1029/2002JD002165, 2003.

Bond, T. C., Streets, D. G., Yarber, K. F., Nelson, S. M., Woo, J.H., and Klimont, Z.: A technology-based global inventory of black and organic carbon emissions from combustion, J. Geophys. Res., 109, D1423, doi:10.1029/2003JD003697, 2004.

Bond, T. C. and Bergstrom, R. W.: Light absorption by carbonaceous particles: An investigative review, Aerosol Sci. Tech., 40, 27-67, 2006.

Bond, T. C., Habib, G., and Bergstrom, R. W.: Limitations in the enhancement of visible light absorption due to mixing state, J. Geophys. Res., 111, D20211, doi:10.1029/2006JD007315, 2006.

Canagaratna, M. R., Jayne, J. T., Jimenez, J. L., Allan, J. D., Alfarra, M. R., Zhang, Q., Onasch, T. B., Drewnick, F., Coe, H., Middlebrook, A., Delia, A., Williams, L. R., Trimborn, A. M., Northway, M. J., DeCarlo, P. F., Kolb, C. E., Davidovits, P., and Worsnop, D. R.: Chemical and microphysical characterization of ambient aerosols with the aerodyne aerosol mass spectrometer, Mass Spectrom. Rev., 26, 185-222, 2007.

Carrico, C. M., Kreidenweis, S. M., Malm, W. C., Day, D. E., Lee, T., Carrillo, J., McMeeking, G. R., and Collett Jr., J. L.: Hygroscopic growth behavior of carbon-dominated aerosol in Yosemite National Park, Atmos. Environ., 39, 1393-1404, 2005.

Carrico, C. M., Petters, M. D., Kreidenweis, S. M., Collett Jr., J. L., Engling, G., and Malm, W. C.: Aerosol hygroscopicity and cloud droplet activation of extracts of filters from biomass burning experiments, J. Geophys. Res., 113, D08206, doi:10.1029/2007JD009274, 2008.

Chakrabarty, R. K., Moosmüller, H., Garro, M. A., Arnott, W. P., Walker, J., Susott, R. A., Babbitt, R. E., Wold, C. E., Lincoln, E. N., and Hao, W. M.: Emissions from the laboratory combustion of wildland fuels: Particle morphology and size, J. Geophys. Res., 111, D07204, doi:10.1029/2005JD006659, 2006.

Chakrabarty, R. K., Moosmüller, H., Arnott, W. P., Garro, M. A., Slowik, J. G., Cross, E. S., Han, J.-H., Davidovits, P., Onasch, T. B., and Worsnop, D. R.: Light scattering and absorption by fractal-like carbonaceous chain aggregates: Comparison of theories and experiment, Appl. Optics, 46, 6990-7006, 2007.

Chamberlain, A. C., Clough, W. S., Heard, M. J., Newton, D., Stott, A. N. B., and Wells, A. C.: Uptake of lead by inhalation of motor exhaust, Proceedings of the Royal Society of London, Series B, Biol. Sci., 192, 77-110, 1975.

Colbeck, I., Atkinson, B., and Johar, Y.: The morphology and optical properties of soot produced by different fuels, J. Aerosol Sci., 28, 715-723, 1997.

Day, D. E., Hand, J. L., Carrico, C. M., Engling, G., and Malm, W. C.: Humidification factors from laboratory studies of fresh smoke from biomass fuels, J. Geophys. Res., 111, D22202, doi:10/1029/2006JD007221, 2006.

DeCarlo, P. F., Slowik, J. G., Worsnop, D. R., Davidovits, P., and Jimenez, J. L.: Particle morphology and density characterization by combined mobility and aerodynamic diameter measurements, Part 1: Theory, Aerosol Sci. Tech., 38, 1185-1205, 2004.

DeCarlo, P. F., Kimmel, J. R., Trimborn, A., Northway, M. J., Jayne, J. T., Aiken, A. C., Gonin, M., Fuhrer, K., Horvath, T., Docherty, 
K. S., Worsnop, D. R., and Jimenez, J. L.: Field-deployable, high-resolution, time-of-flight aerosol mass spectrometer, Anal. Chem., 78, 8281-8289, 2006.

Ebert, M., Inerle-Hof, M., and Weinbruch, S.: Environmental scanning electron microscopy as a new technique to determine the hygroscopic behaviour of individual aerosol particles, Atmos. Environ., 36, 5909-5916, 2002.

Fuller, K. A.: Scattering of light by coated spheres, Opt. Lett., 18, 257-259, 1993.

Fuller, K. A., Malm, W. C., and Kreidenweis, S. M.: Effects of mixing on extinction by carbonaceous particles, J. Geophys. Res., 104, 15941-15954, 1999.

Hallett, J., Hudson, J. G., and Rogers, C. F.: Characterization of combustion aerosols for haze and cloud formation, Aerosol Sci. Tech., 10, 70-83, 1989.

Hand, J. L., Malm, W. C., Laskin, A., Day, D., Lee, T., Wang, C., Carrico, C., Carrillo, J., Cowin, J. P., Collett Jr., J. L., and Iedema, M. J.: Optical, physical, and chemical properties of tar balls observed during Yosemite Aerosol Characterization Study, J. Geophys. Res., 110, D21210, doi:10.1029/2004JD005728, 2005.

Hopkins, R. J., Lewis, K., Desyaterik, Y., Wang, Z., Tivanski, A. V., Arnott, W. P., Laskin, A., and Gilles, M. K.: Correlations between optical, chemical and physical properties of biomass burn aerosols, Geophys. Res. Lett., 34, L18806, doi:10.1029/2007GL030502, 2007a.

Hopkins, R. J., Tivanski, A. V., Marten, B. D., and Gilles, M. K.: Chemical bonding and structure of black carbon reference materials and individual carbonaceous atmospheric aerosols, J. Aerosol Sci., 38, 573-591, 2007b.

Huang, P.-F., Turpin, B. J., Pipho, M. J., Kittelson, D. B., and McMurry, P. H.: Effects of water condensation and evaporation on diesel chain-agglomerate morphology, J. Aerosol Sci., 25, 447459, 1994

Huffman, J. A., Docherty, K. S., Mohr, C., Cubison, M. J., U1brich, I. M., Ziemann, P. J., Onasch, T. B., and Jimenez, J. L.: Chemically-resolved volatility measurements of organic aerosol from different sources, Environ. Sci. Technol., 43, 5351-5357, 2009.

Jacobson, M. Z.: Strong radiative heating due to the mixing state of black carbon in atmospheric aerosols, Nature, 409, 695-697, 2001.

Jimenez, J. L., Bahreini, R., Cocker, D. R. I., Zhuang, H., Varutbangkul, V., Flagan, R. C., Seinfeld, J. H., O’Dowd, C. D., and Hoffmann, T.: New particle formation from photooxidation of diiodomethane $\left(\mathrm{CH}_{2} \mathrm{I}_{2}\right)$, J. Geophys. Res., 108(D10), 4318, doi:10.1029/2002JD002452, 2003.

Köylü, Ü. Ö., Faeth, G. M., Farias, T. L., and Carvalho, M. G.: Fractal and projected structure properties of soot aggregates, Combust. Flame, 100, 621-623, 1995.

Laskin, A. and Cowin, J. P.: Automated single-particle SEM/EDX analysis of submicrometer particles down to $0.1 \mu \mathrm{m}$, Anal. Chem., 73, 1023-1029, 2001.

Laskin, A., Cowin, J. P., and Iedema, M. J.: Analysis of individual environmental particles using modern methods of electron microscopy and X-ray microanalysis, J. Electron Spectrosc., 150, 260-274, 2006.

Lewis, K., Arnott, W. P., Moosmüller, H., and Wold, C.: Strong spectral variation of biomass smoke light absorption and single scattering albedo observed with a novel dual wavelength photoacoustic instrument, J. Geophys. Res., 113, D16203, doi:10.1029/2007JD009699, 2008.

Liu, B. Y. H., Pui, D. Y. H., Whitby, K. T., and Kittelson, D. B.: The aerosol mobility chromograph: A new detector for sulfuric acid aerosols, Atmos. Environ., 12, 99-104, 1978.

Liu, L. and Mishchenko, M. I.: Effects of aggregation on scattering and radiative properties of soot aerosols, J. Geophys. Res., 110, D11211, doi:10.1029/2004JD005649, 2005.

Liu, L., Mishchenko, M. I., and Arnott, W. P.: A Study of radiative properties of fractal soot aggregates using the superposition $T$ matrix method, J. Quant. Spectrosc. Ra., 109, 2656-2663, 2008.

Lunnon, R. G.: The latent heat of evaporation of aqueous salt solutions, P. Phys. Soc. Lond., 25, 180-191, 1913.

McMeeking, G., Kreidenweis, S. M., Baker, S., Carrico, C. M., Chow, J. C., Collett Jr., J. L., Hao, W. M., Holden, A. S., Kirchstetter, T. W., Malm, W. C., Moosmüller, H., Sullivan, A. P., and Wold, C.: Emissions of trace gases and aerosols during the open combustion of biomass in the laboratory, J. Geophys. Res., 114 D19210, doi:10.1029/2009JD011836, 2009.

McMeeking, G. R.: The optical, chemical and physical properties of aerosols and gases emitted by the laboratory combustion of wildland fuels, Doctor Philosophy, Department of Atmospheric Science, Colorado State University, Fort Collins, 298 pp., 2008.

Mikhailov, E. F., Vlasenko, S. S., Podgorny, I. A., Ramanathan, V., and Corrigan, C. E.: Optical properties of soot-water drop agglomerates: An experimental study, J. Geophys. Res., 111, D07209, doi:10.1029/2005JD006389, 2006.

Moosmüller, H., Kreidenweis, S. M., Collett Jr., J. L., Hao, W. M., and Malm, W. C.: Characterization of particle emissions from laboratory combustion of wildland fuels, iLEAPS Newsletter, 22-23, 2007.

Murphy, D. M.: The effect of water evaporation on photoacoustic signals in transition and molecular flow, Aerosol Sci. Tech., 43, 356-363, 2009.

Nelson, J.: Fractality of sooty smoke: implications for the severity of nuclear winter, Nature, 339, 611-613, 1989.

Rader, K. J. and McMurry, P. H.: Application of the tandem differential mobility analyzer to studies of droplet growth and evaporation, J. Aerosol Sci., 17, 771-787, 1986.

Ramanathan, V., Crutzen, P. J., Kiehl, J. T., and Rosenfeld, D.: Aerosols, climate, and the hydrological cycle, Science, 294, 2119-2124, 2001.

Raspet, R., Hickey, C. J., and Sabatier, J. M.: The effect of evaporation-condensation on sound propagation in cylindrical tubes using the low reduced frequency approximation, J. Acoust. Soc. Am., 105, 65-73, 1999.

Raspet, R., Slaton, W. V., Arnott, W. P., and Moosmüller, H.: Evaporation-condensation effects on resonant photoacoustics of volatile aerosols, J. Atmos. Ocean. Tech., 20, 685-695, 2003.

Rissler, J., Pagels, J., Swietlicki, E., Wierzbicka, A., Strand, M., Lillieblad, L., Sanati, M., and Bohgard, M.: Hygroscopic behavior of aerosol particles emitted from biomass fired grate boilers, Aerosol Sci. Tech., 39, 919-930, 2005.

Schnaiter, M., Horvath, H., Möhler, O., Naumann, K. H., Saathoff, H., and Schöck, W.: UV-VIS-NIR spectral optical properties of soot and soot-containing aerosols, J. Aerosol Sci., 34, 14211444, 2003.

Slowik, J. G., Cross, E. S., Han, J.-H., Davidovits, P., Onasch, T. B., 
Jayne, J. T., Williams, L. R., Canagaratna, M. R., Worsnop, D. R., Chakrabarty, R. K., Moosmüller, H., Arnott, W. P., Schwarz, J. P., Gao, R.-S., Fahey, D. W., Kok, G. L., and Petzold, A.: An Inter-comparison of instruments measuring black carbon content of soot particles, Aerosol Sci. Tech., 41, 295-314, 2007.

Solomon, S., Qin, D., Manning, M., Chen, Z., Marquis, M., Averyt, K. B., Tignor, M., and Miller, H. L.: Climate change 2007: The physical science basis, IPCC Secretariat, Geneva, Switzerland, 2007.

Sorensen, C. M. and Roberts, G. C.: The prefactor of fractal aggregates, J. Colloid Interf. Sci., 186, 447-452, 1997.

Sorensen, C. M.: Light scattering by fractal aggregates: A review, Aerosol Sci. Tech., 35(2), 648-687, 2001.

Weingartner, E., Baltensperger, U., and Burtscher, H.: Growth and structural change of combustion aerosols at high relative humidity, Environ. Sci. Technol., 29, 2982-2986, 1995.
Weingartner, E., Burtscher, H., and Baltensperger, U.: Hygroscopic properties of carbon and diesel soot particles, Atmos. Environ., 31, 2311-2327, 1997.

Westerling, A. L., Hidalgo, H. G., Cayan, D. R., and Swetnam, T. W.: Warming and earlier spring increase western US forest wildfire activity, Science, 313, 940-943, 2006.

Zhang, X. Q., McMurry, P. H., Hering, S. V., and Casuccio, G. S.: Mixing characteristics and water content of submicron aerosols measured in Los Angeles and at the Grand Canyon, Atmos. Environ., 27, 1593-1607, 1993.

Zuberi, B., Johnson, K. S., Aleks, G. K., Molina, L. T., Molina, M. J., and Laskin, A.: Hydrophilic properties of aged soot, Geophys. Res. Lett., 32, L01807, doi:10.1029/2004GL021496, 2005. 